\title{
Apontamentos para o debate sobre o pleno emprego no Brasil *
}

\author{
Fernando Augusto Mansor de Mattos ** \\ Sergiany da Silva Lima ***
}

\begin{abstract}
Resumo
Este artigo analisa a evolução dos indicadores de emprego e de desemprego na economia brasileira desde o início dos anos 2000 até os dados referentes a 2012, tomando como referências teóricas a formulação de Keynes sobre o desemprego involuntário e também os estudos sobre a dinâmica das relações entre setor formal e setor informal dos mercados de trabalho formulados por autores ligados ao Prealc. O artigo apresenta um exercício econométrico (que teve por base a função emprego de Keynes explicada pelo Princípio da Demanda Efetiva) que revela que o crescimento do emprego é uma função positiva do crescimento econômico. Dados adicionais mostram que, a despeito do crescimento da ocupação e da formalização do emprego ocorrida no período, com consequente queda da taxa de desemprego para patamares historicamente baixos, a economia brasileira não conseguiu, segundo as referências teóricas adotadas, atingir o pleno emprego ao final do período analisado, devido à persistência de parcela expressiva de mão de obra subutilizada no mercado de trabalho.
\end{abstract}

Palavras-chave: Pleno emprego; Mercado de trabalho brasileiro; Taxa de desemprego no Brasil; Setor informal; Demanda efetiva em Keynes.

\section{Abstract \\ Observations on the debate on full employment in Brazil}

The article examines the evolution of employment and unemployment in Brazil, from 2000 to 2012. It uses, as theoretical references, the argument about involuntary unemployment made by Keynes, and studies on the relationship between the formal and informal sectors of the labor market carried out by authors connected to the Prealc. An econometric model, based on Keynes's employment function (which is based on the Principle of Effective Demand) reveals that employment is positively correlated with economic growth. Additional data show that despite the growth in occupation and in job formalization during the period, which caused unemployment rates to plummet to historically low figures, the Brazilian economy did not achieve full employment. According to the theoretical references adopted, this was largely because a sizable portion of the labor force remained underutilized.

Keywords: Full employment; Brazilian labor market; Rate of unemployment in Brazil; Informal sector; Keynes' effective demand.

JEL J00, J21, J60.

* Trabalho recebido em 14 de maio de 2013 e aprovado em 8 de maio de 2015. Os autores agradecem à economista Julia de Medeiros Braga (UFF) pela ajuda na elaboração do exercício econométrico e de outras partes do texto, eximindo-a, porém, de eventuais imprecisões ainda remanescentes.

** Professor/Pesquisador no Programa de Pós-Graduação (PPGE) da Faculdade de Economia da Universidade Federal Fluminense (UFF), Niterói, RJ, Brasil. E-mail: fermatt1 @ hotmail.com.

${ }^{* * *}$ Professor assistente do curso de Economia da Universidade Federal Rural de Pernambuco/Unidade

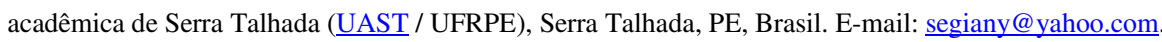




\section{Apresentação}

Este artigo pretende investigar se o crescimento econômico ocorrido desde meados da primeira década dos anos 2000 até o ano de 2012 foi suficiente para que a economia brasileira atingisse o pleno emprego. O marco teórico da análise dos dados repousa na formulação da Teoria Geral de Keynes (Keynes, 1988[1936]) e também na contribuição de autores ligados à tradição de estudos sobre o desenvolvimento da América Latina, mais especificamente os autores que fizeram parte do Prealc ${ }^{1}$.

$\mathrm{Na}$ interpretação de Keynes, as expectativas de curto prazo relacionam-se a alterações nas condições da demanda efetiva, dada a capacidade instalada na economia. Este artigo trabalha com este referencial, presente na Teoria Geral, para avaliar a hipotética situação de pleno emprego da economia brasileira no período acima referido.

O Princípio da Demanda Efetiva de Keynes postula que o nível de emprego resulta das decisões de investimento e de consumo tomadas na economia capitalista. A análise de Keynes, porém, não é suficiente ${ }^{2}$ para interpretar a questão do emprego em uma economia subdesenvolvida, como a brasileira. Sua análise baseou-se na realidade de economias desenvolvidas (e foi inspirada por fatos de um momento histórico específico, a Grande Depressão dos anos 1930), nas quais o problema central era a subutilização da capacidade produtiva instalada.

No caso de países da América Latina, a problemática do emprego era diferente da abordada por Keynes na Teoria Geral. O debate era sobre a necessidade (e as condições políticas, institucionais e econômicas para tal intento ser atingido) de ampliar a capacidade produtiva, ou seja, pela necessidade de industrialização. É nesse contexto que as questões ligadas ao emprego, à distribuição de renda e à

(1) O Prealc (Programa Regional del Empleo para América Latina y el Caribe) foi criado já no final dos anos 1960 pela OIT (Organização Internacional do Trabalho), em um contexto em que diversos programas regionais foram criados, para os demais continentes. O objetivo da criação do Prealc era discutir o processo de desenvolvimento econômico na América Latina de tal maneira a sugerir estratégias para a expansão do emprego e dos rendimentos como forma de superar o atraso social do continente (Cacciamali, 1983). Os pesquisadores do PREALC estavam em sintonia com o pensamento da Cepal (Comissão Econômica para a América Latina e o Caribe), a respeito da realidade latino-americana, considerando que o crescimento econômico que vinha ocorrendo na maioria desses países, nas décadas recentes (em que a maior parte deles já havia passado por processo de industrialização), não tinha sido suficiente para promover estruturação dos mercados de trabalho, superação da pobreza e homogeneização social. Para mais detalhes do contexto histórico que norteou a criação do Prealc, ver: Krein e Proni (2010).

(2) Daí decorre a necessidade de incluir aparato teórico específico para a análise da realidade de um país de economia "atrasada", desde que, evidentemente - como é o caso - esse referencial teórico específico para economias subdesenvolvidas não seja incompatível com o referencial keynesiano. 
superação da pobreza, surgem, nos anos 1950, de forma mais organizada, a partir da criação da $\mathrm{Cepal}^{3}$.

Neste artigo, a análise dos dados do mercado de trabalho da economia brasileira, no período em tela, terá como referência teórica o Princípio da Demanda Efetiva, formulado por Keynes na Teoria Geral. A esse referencial serão somadas as contribuições dos autores do Prealc, notadamente Souza (1980a), cuja produção teórica, reconhecidamente, representa o amadurecimento das formulações conceituais dos pesquisadores do Prealc. O aspecto da obra de Souza (1980 a) a ser destacado refere-se especificamente à dinâmica da constituição e do relacionamento entre os segmentos formal e informal do mercado de trabalho, tendo por objetivo investigar a problemática da geração de emprego e renda em economias subdesenvolvidas como as do subcontinente.

O presente estudo está dividido em quatro partes, além desta apresentação e das conclusões. Na primeira parte, são apresentados, de forma sucinta, os principais argumentos presentes na Teoria Geral de Keynes acerca da determinação do nível de emprego segundo o Princípio da Demanda Efetiva, destacando-se o conceito de pleno emprego para Keynes. Na segunda parte, pretendemos sublinhar as principais linhas de formulação teórica do Prealc acerca do relacionamento entre os setores formal e informal nos mercados de trabalho de economias "atrasadas". Estas duas primeiras seções é que darão embasamento teórico para a análise dos dados e para o exercício econométrico formulados nas seções seguintes. $\mathrm{Na}$ terceira parte, são apresentados indicadores do mercado de trabalho brasileiro, destacando-se os dados sobre a evolução da taxa de desemprego no Brasil, segundo diferentes metodologias. As fontes das informações são o IBGE e as Pesquisas de Emprego e Desemprego (PEDs), realizadas em algumas regiões metropolitanas do país. A opção por incluir os dados das Pesquisas de Emprego e Desemprego deve-se ao fato de que as mesmas, segundo argumentamos, refletem de forma mais acurada as diferentes formas de inserção da mão de obra no mercado de trabalho brasileiro, cuja principal característica é justamente a sua elevada heterogeneidade estrutural. Esta elevada heterogeneidade estrutural torna complexos os movimentos da mão de obra entre as situações de ocupação precária, a de desemprego e a situação de inatividade. $\mathrm{Na}$ quarta parte, discute-se a evolução de alguns indicadores do mercado de trabalho

(3) No cenário econômico e político do pós-segunda guerra, o tema do pleno emprego surge como decorrência da consensual necessidade de que o crescimento econômico sustentado e equilibrado entre os países seria uma forma de evitar crises econômicas e geopolíticas como as que haviam levado à deflagração da Segunda Guerra. No pós-segunda guerra, ademais, ficava cada vez mais claro que a hegemonia ideológica repousaria na doutrina e nas práticas de política econômica de extração keynesiana (Belluzzo, 2004), em oposição ao Liberalismo que havia vigorado no entre guerras (Hobsbawm, 1995). É nesse contexto que surgem as pesquisas do Prealc e de outras instituições vinculadas à OIT. 
brasileiro, começando com um exercício econométrico que investiga e permite discutir a relação entre crescimento econômico e evolução do emprego no Brasil no período em questão. A análise proposta pelo exercício econométrico é seguida de análise de outros indicadores de mercado de trabalho brasileiro, procurando mostrar que a referida ampliação do ritmo de geração de emprego ocorrida entre 2003 e 2012 não foi suficiente para eliminar o que foi denominado como subutilização da capacidade laboral de parcelas importantes do mercado de trabalho brasileiro ao final do referido período. Em uma breve subseção, a quarta parte do artigo é finalizada com comentários acerca da heterogeneidade regional brasileira em termos de geração de postos de trabalho no período estudado.

Por fim, nas considerações finais são articuladas as principais conclusões de cada uma das seções, com o objetivo de dar sustentação ao argumento segundo o qual, no período em tela, a economia brasileira não atingiu o pleno emprego, de acordo com as formulações teóricas levadas em conta neste estudo.

\section{A questão do pleno emprego em Keynes e o princípio da demanda efetiva}

Logo no segundo capítulo de sua Teoria Geral, Keynes (1988[1936]) trabalha com a ideia de equilíbrio no curto prazo, mas rejeita a noção de que esta situação de equilíbrio, quando se refere ao mercado de trabalho, seja sempre um ponto de equilíbrio com pleno emprego. Tal situação (de pleno emprego) seria um caso excepcional, e não o caso geral. Macedo e Silva (1999) define o que seria, para Keynes, a situação de equilíbrio com pleno emprego: “(...) numa situação de pleno emprego, igualam-se a oferta (por parte dos trabalhadores) e a demanda (por parte dos capitalistas) de trabalho. No pleno emprego, todos os indivíduos que, nas condições vigentes, desejam trabalhar, já estão empregados" (Macedo e Silva, p. 159). Keynes, porém, trabalha com a hipótese de que esta situação de pleno emprego somente será (ou seria) atingida quando o total de gastos que configuram a demanda efetiva na economia for capaz de gerar a renda de pleno emprego, ou seja, aquela que estabelece um nível de produção alto o suficiente para que recursos produtivos (como máquinas e mão de obra) não fiquem ociosos. Esta situação dependerá dos fatores que causam, respectivamente, as decisões de investir (por parte dos capitalistas) e de consumir (por parte dos consumidores), conforme comentaremos mais à frente. Por enquanto, é necessário destacar que, para Keynes, a situação de pleno emprego significa, literalmente, que os recursos econômicos disponíveis estão plenamente utilizados, sendo possível, nesta situação, apenas a existência de alguma forma de desemprego friccional (e também de desemprego 
involuntário, além de residual) (Carvalho, 2011), quando um restrito número de trabalhadores estaria transitando de um emprego a outro ${ }^{4}$.

Para compreender esta situação, deve-se destacar o significado do Princípio da Demanda Efetiva, para Keynes e, em especial, o papel desempenhado pela moeda em uma economia capitalista, que Keynes interpreta como uma "economia monetária da produção" (Belluzzo, 2004).

$\mathrm{Na}$ Teoria Geral, fica claro que a moeda desempenha mais do que simplesmente a função de unidade de conta ou de meio de pagamento. A rigor, segundo Keynes, a moeda é a finalidade última da atividade produtiva, no sentido de que o objetivo do empresário, conduzido pelas engrenagens de funcionamento da concorrência intercapitalista, é de valorizar a riqueza (medida em termos monetários), podendo este processo operar-se na esfera da produção (a partir do momento em que o empresário abre mão da liquidez para adquirir equipamentos, matérias-primas e contratar mão de obra para colocar em funcionamento os bens de capital) ou na esfera financeira. Keynes registra que o detentor da moeda pode sempre optar por entesourá-la - situação não prevista, por exemplo, na Lei de Say, que supõe que toda produção cria sua própria demanda e que a moeda é um mero veículo para viabilizar as trocas.

Desta forma, a diferença central entre a interpretação de Keynes e a proposição clássica reside na interpretação do papel exercido pela moeda (Belluzzo, 2004). Interpretando a obra de Keynes, Carvalho (2011) mostra que a possibilidade de os portadores de riqueza reterem moeda (dada a sua função de reserva de valor e, portanto, a sua característica de portadora de riqueza abstrata, e que pode ser gasta a qualquer momento) caracteriza a natureza do capitalismo e delimita as decisões de gastos dos agentes, notadamente daqueles que têm em seu poder o comando das decisões de investir e, assim, de gerar produção (e emprego). Desta forma, ao reter a moeda, postergando o gasto, o capitalista está "gerando" desemprego e tal suposição não se trata de uma situação excepcional ou isolada sob o capitalismo, mas sim de sua situação mais geral e corriqueira.

(4) Um conceito mais utilizado a partir da década de 1970 é o da Nairu (non-acelerating inflation rate of unemployment). Para os autores que consideram que todo desemprego é friccional, a Nairu é igual à taxa natural de desemprego (ou seja, aquela vigente em uma situação de pleno emprego). Nesse caso, a velha crítica keynesiana da existência de desemprego involuntário se aplica. Porém, para muitos autores, a Nairu se distingue da taxa natural de desemprego, no sentido de não requerer que haja pleno emprego no mercado de trabalho. Nesse caso, pode haver desemprego involuntário e a Nairu seria a única compatível com a inexistência de conflito distributivo (ver Carlin; Soskice, 1990 para uma formulação teórica sobre esse aspecto e Stirati, 2001 para uma crítica à mesma). Dessa forma, esse conceito ganhou a simpatia de muitos economistas por ser supostamente isento de "visões teóricas", constituindo-se apenas de uma definição estatística. Porém, o conceito tampouco é útil do ponto de vista de política econômica devido à grande dificuldade empírica de se estimá-lo. Esta dificuldade ficou evidente nos anos 1980, no debate sobre desemprego nas economias europeias, associado ao fenômeno da histerese, assim como na segunda metade dos anos 1990, na economia americana (ver Ball; Mankiw, 2002, para uma resenha deste debate). 
O Princípio da Demanda Efetiva (definido no terceiro capítulo da Teoria Geral) postula que os gastos são decididos em condições de incerteza e eles é que geram a renda e, portanto, o nível de emprego. A equação da demanda efetiva (supondo-se uma economia fechada e sem governo, para simplificar) tem dois elementos: o consumo e o investimento. Para entender o nível de emprego e renda gerados pela demanda efetiva, é preciso compreender os respectivos fatores que comandam as decisões de consumir (e que determinam a propensão a consumir) e de investir. Não é objetivo deste estudo fazer uma análise ou tampouco uma descrição (mesmo que sumária) dos fatores que governam as decisões de consumir e de investir 5 . O Princípio da Demanda Efetiva postula que são os gastos que determinam a renda e, assim, para Keynes, a função da demanda por trabalho não é determinada no próprio mercado de trabalho, mas resulta das decisões de gastos dos agentes econômicos, destacando-se os gastos dos empresários. Para Keynes, os empresários somente decidirão abrir mão da liquidez (adquirindo equipamentos, por exemplo, ou seja, efetuando investimentos) caso tenham a expectativa de que os custos monetários envolvidos na tomada de decisão de investir serão suplantados, no futuro, pelas receitas (medidas na forma monetária) auferidas pelas vendas dos produtos. Esta é a decisão crucial a ser tomada em uma economia capitalista e dela depende o nível de emprego gerado no futuro. Os trabalhadores não podem decidir "conseguir" um emprego; os empresários é que podem decidir empregar seus recursos em novos equipamentos ou na expansão do uso dos equipamentos já instalados. Dadas as condições de incerteza com que operam os capitalistas e considerando que a moeda é, em última instância, o bem que todos almejam e que serve como forma de avaliação da riqueza, podem existir motivos para que os empresários decidam, em algum momento e por algum período, não efetuar gastos e então a economia operaria em um ponto abaixo do que seria o pleno emprego, surgindo, assim, o desemprego involuntário da mão de obra. É esta possibilidade (que não é nada excepcional, pelo contrário, é bem trivial) de se manter na liquidez que gera, para Keynes, a possibilidade de a economia operar sob desemprego (ou em um ponto de equilíbrio abaixo do nível de pleno emprego).

É com base nesta concepção teórica que este artigo pretende discutir a situação do hipotético pleno emprego da economia brasileira no período que vai até dezembro de 2012. Tanto o exercício econométrico realizado para compreender e relacionar crescimento do PIB, ampliação do emprego e formalização do mercado de trabalho, quanto a análise dos indicadores de mercado de trabalho tomarão as formulações de Keynes como referência. Porém, como estamos tratando de uma

(5) Em poucas palavras: fatores psicológicos, no caso do consumo; e interação entre a chamada eficiência marginal do capital versus taxa de juros, no caso do investimento. Neste último caso, Keynes destaca que aspectos de incerteza em relação ao futuro influenciam as decisões de aumentar a capacidade de produção (investir). 
economia de capitalismo tardio, optamos por agregar as formulações do Prealc para analisar a parte empírica deste estudo, em suas duas últimas seções.

Antes das seções de análise de dados e do exercício econométrico, porém, devemos destacar na seção a seguir, em linhas gerais, a contribuição teórica dos autores vinculados ao Prealc.

\section{A contribuição teórica do Prealc para o debate sobre mercado de trabalho e informalidade}

As formulações teóricas de Keynes foram elaboradas tendo como referência a realidade de economias capitalistas desenvolvidas que passavam por um momento de pronunciada subutilização da capacidade produtiva (industrial, especialmente) instalada.

A realidade das economias "atrasadas" (Souza, 1980a) (ou subdesenvolvidas) é outra, pois as mesmas, conforme foi destacado pelos autores que fizeram parte da chamada Teoria do Desenvolvimento ${ }^{6}$ (cujas principais obras foram formuladas a partir dos anos 1950), careciam justamente de investimentos e de capacidade produtiva para enfrentar o problema do atraso econômico crônico e a necessidade de superar a pobreza e gerar empregos.

No caso da América Latina, uma ampla agenda de pesquisas se desenvolveu entre pensadores sociais que se uniram no Prealc, acolhidos nos anos 1970 pela Cepal. O objetivo destes pesquisadores era compreender os efeitos do processo de industrialização (na época, já em curso há cerca de 25 anos) sobre os mercados de trabalho, destacando as novas formas de organização da produção e, em especial, a determinação da renda e da ocupação nas atividades não tipicamente capitalistas (Souza, 1980a). Tal esforço teórico repousa na investigação acerca da relação dinâmica entre as chamadas atividades do setor informal e as atividades tipicamente capitalistas.

O referido trabalho (Souza, 1980a) significou o amadurecimento de uma agenda de pesquisas que se opunha aos estudos iniciais sobre as relações entre setor formal e setor informal, os quais postulavam que, com o passar dos anos e com o processo de desenvolvimento capitalista nos países subdesenvolvidos, o setor informal gradativamente seria eliminado, em favor dos novos setores que seriam progressivamente instalados, à medida que o desenvolvimento econômico se consolidasse.

(6) Ver Bastos e Britto (2010): “A teoria do desenvolvimento que surge após a Segunda Guerra Mundial não escapa à regra de outros avanços da teoria econômica. É fruto de seu tempo, das condições sociais e ideológicas que marcam tanto o seu nascimento quanto a forma geral que assume. Esse período se caracteriza por fortes pressões sociais e políticas, nacionais e internacionais, pelo desenvolvimento de países que estavam em estágio de avanço econômico e material inferior aos países mais ricos" (p. 8). 
Souza (1980a) baseia sua análise do funcionamento do setor informal interpretando-o pela ótica das relações de produção, destacando a contínua transformação das características e das formas de integração entre os setores formal e informal, ou, em outra nomenclatura, entre as atividades tipicamente capitalistas e as não tipicamente capitalistas. Entre as principais preocupações desses autores, estava a de compreender os fatores determinantes dos níveis de rendimentos nos setores não tipicamente capitalistas ou no setor informal dos respectivos mercados de trabalho. Para o que nos interessa discutir neste artigo, porém, basta-nos destacar outra preocupação da formulação teórica do Prealc: os mecanismos de mobilidade das pessoas entre os setores e os fatores que explicam a interação entre as diferentes formas de organização da produção.

Souza (1980a) advoga pela existência de uma primazia das formas tipicamente capitalistas sobre as demais formas de organização da produção, no sentido de que as primeiras é que, em sua dinâmica de acumulação, determinam os espaços de atuação das formas não típicas de organização capitalista e também - por suposto - delimitam a estrutura ocupacional do conjunto da economia.

Para Souza (1980a), a acumulação capitalista ocorre em um contexto de já adiantado processo de divisão social do trabalho, ampliando-a continuamente. A escala de produção, para o autor, define situações concorrenciais, nos diferentes mercados, em favor das empresas organizadas na forma tipicamente capitalista, em detrimento da "pequena produção" ou das "formas não tipicamente capitalistas". Na seguinte passagem, Souza (1980a) deixa clara a sua formulação a respeito da dinâmica da relação entre os setores formal e informal (que ele chama, respectivamente, de tipicamente capitalista e de não tipicamente capitalista ou "pequena produção"): "o núcleo verdadeiramente capitalista de uma economia, no seu movimento de expansão, cria, destrói e recria os espaços econômicos nos quais atua a pequena produção não tipicamente capitalista. É neste sentido, também, que podemos dizer que os espaços econômicos da pequena produção são perfeitamente determinados pelo núcleo capitalista. Isto significa que a pequena produção não tem capacidade de gerar seu próprio espaço econômico em uma economia em que o capital já é dominante" (grifo dos autores).

Esta interpretação a respeito da relação dinâmica entre o "núcleo verdadeiramente capitalista" e as atividades da "pequena produção" merece ser destacada aqui, pois é a ela que remetemos a discussão sobre a migração dos trabalhadores entre diferentes formas de inserção no mercado de trabalho (entendido em seu aspecto mais amplo, ou seja, não apenas pela situação do assalariamento formal nas atividades capitalistas, mas também das formas de trabalho no setor informal ou não tipicamente capitalista) e, por conseguinte, à discussão sobre subutilização do fator trabalho. Tais considerações são importantes para se avaliar supostas situações de pleno emprego em economias subdesenvolvidas. Essa situação de pleno emprego, segundo Keynes, seria aquela em que todos os fatores de 
produção estariam plenamente empregados (dadas as considerações já sublinhadas na primeira seção deste artigo). Adicionalmente, devemos destacar que, segundo a literatura do Prealc, referendada pelo próprio Souza, a existência de significativas parcelas do setor informal revelaria não somente (em termos semelhantes ao de Keynes) uma situação em que fatores de produção não estariam plenamente empregados, como tampouco estariam adequadamente empregados ${ }^{7}$, segundo Souza (1980a).

O processo de acumulação capitalista provoca modificações não apenas no núcleo dinâmico e formal da economia; promove também variadas alterações na composição da PEA (População Economicamente Ativa, conceito consagrado pelas pesquisas de emprego e desemprego atualmente existentes), que é composta não somente pelos assalariados formais dos setores tipicamente capitalistas, mas por toda uma ampla gama de ocupados nos segmentos informais do mercado de trabalho, como por exemplo os donos de pequenos negócios não organizados da forma capitalista, assim como por trabalhadores autônomos (ou também denominados trabalhadores por conta própria), ou que produzem apenas para autoconsumo ou ainda para vender sua produção (de bens e/ou serviços) no mercado.

A destruição de formas não tipicamente capitalistas de produção pode levar essas pessoas a procurarem se inserir nas atividades dos setores capitalistas e dinâmicos que produziram aquela modificação no seu próprio espaço econômico original ou então pode levá-las a procurar outras atividades também não organizadas na forma capitalista, quer seja na mesma região ou mesmo em outros locais em que a atividade mais organizada e mais capitalizada ainda não tenha chegado.

Da mesma forma, os "excluídos" dos setores modernos podem se dividir em diferentes situações. Podem se colocar em situação de "criar" suas próprias ocupações ou vivenciar períodos em que fazem parte da PEA, mas estão desempregados $^{8}$. Ou, no limite, podem retirar-se da PEA, temporariamente ou não, tornando-se inativos e deixando de "pressionar" o mercado de trabalho. Dependendo de diversas circunstâncias econômicas, podem ou não voltar a procurar um emprego

(7) Daí decorre a expressão "não tipicamente capitalistas", de Souza (1980a).

(8) Cacciamali (1982), na mesma linha adotada pela contribuição teórica de Souza (1980a), que destaca a primazia do setor formal no processo de acumulação, descreve a natureza desses movimentos da mão de obra entre diferentes formas de inserção nos espaços ocupacionais, na seguinte passagem: "quando o capital captura uma atividade dominada por produtores informais, esses são, em geral, destruídos por firmas que absorvem relativamente menos trabalho em virtude de apresentarem patamar de produtividade mais elevado. Simultaneamente, a produção capitalista como um todo pode ampliar esse mercado específico ou, então, plantas adicionais podem ser introduzidas em outros ramos e mercados._Os trabalhadores informais nesta situação se assalariam, deslocam-se para outra atividade informal, ficam desempregados ou são obrigados a abandonarem temporária ou definitivamente a produção. Isso dependerá, principalmente, do vigor, do ritmo e do padrão de crescimento econômico e, portanto, das opções de postos de trabalho oferecidos pelo conjunto dos ramos e atividades econômicas, pelas formas de organização capitalista e pelo espaço econômico permissível às atividades informais" (itálico da autora). 
ou a atuar em alguma forma de ocupação em alguma unidade produtiva pertencente à ampla gama de atividades que constituem o setor informal.

Tokman (1987), comentando a evolução da interpretação do conceito de setor informal ${ }^{9}$ na literatura sobre o tema, permite depreender os efeitos que o ciclo econômico tem sobre as formas de inserção dos trabalhadores no mercado de trabalho. Em momentos de retração da atividade econômica, com consequente redução do nível de atividade do setor moderno (formal), o setor informal torna-se uma opção ocupacional a ser buscada pelos trabalhadores desempregados pelo processo produtivo dos setores modernos. Por outro lado, quando o ciclo econômico torna-se ascendente, existe a possibilidade de que, além da recuperação do nível de emprego no setor formal, também sejam criadas novas atividades no setor informal, justamente porque estas atividades são subordinadas à dinâmica do setor formal. Em ambas as situações do ciclo econômico, habitualmente ocorrem migrações de trabalhadores entre diferentes situações de inserção no mercado de trabalho. No caso da economia em situação de ciclo descendente, o trabalhador eventualmente demitido do setor formal pode inicialmente passar para uma situação de desemprego aberto ou então diretamente passar para uma ocupação precária do setor informal, ainda que se mantivesse na postura de procurar outro emprego (o que, na metodologia da $\mathrm{PED}^{10}$, por exemplo, o caracterizaria como em situação de "desemprego oculto pelo trabalho precário"). No caso do ciclo econômico em alta, podem ocorrer diversas situações como, por exemplo, de casos "extremos", como o de uma situação que a PED classificaria um trabalhador que passaria da situação de "desemprego oculto pelo desalento" para uma situação de emprego formal ou, pelo menos, de uma situação em que o trabalhador transitaria de uma situação de inatividade para uma situação de ocupação no setor informal, auferindo algum rendimento e procurando ou não uma nova ocupação no período em que se encontra exercendo essa atividade.

O importante a salientar, porém, tendo em conta os marcos teóricos definidos por Souza (1980a) e a análise retrospectiva que Tokman (1987) organiza em seu artigo sobre o setor informal, é que, de todo modo, as mudanças ocorridas no setor informal são subordinadas à dinâmica do setor formal (ou o setor verdadeiramente capitalista) e promovem alterações nas condições de inserção dos trabalhadores nos

(9) O referido artigo foi escrito em 1987, quinze anos após a OIT ter publicado um estudo pioneiro sobre o setor informal, em pesquisa feita no Kenya (OIT, 1972). Naquele estudo, o setor informal fora interpretado simplesmente como se fossem atividades em oposição ao setor formal e pouco relacionadas a este. Tokman (1987) reconhece o avanço ocorrido na conceituação dessas atividades, destacando o papel que o trabalho de Souza (1980a e 1980b) desempenhou na compilação das interpretações até então já existentes sobre o setor informal, consolidando uma conceitualização que se tornaria clássica e que passaria a representar o amadurecimento dos primeiros esforços feitos pelo Prealc sobre o tema. Souza (1980a e também 1980b) define o setor informal pela natureza de suas funções no espaço econômico e considera que o mesmo deve ser avaliado pelas suas atividades remuneradas (excluindo, portanto, atividades de mero autoconsumo, por exemplo).

(10) Na próxima seção é feita uma descrição da metodologia que define as formas de inserção no mercado de trabalho, tanto no caso da PED quanto no caso da PME, do IBGE. 
mercados de trabalho; ademais - e isso é muito importante ao que nos interessa discutir aqui -, fica implícito que, existindo pessoas atuando em atividades do setor informal, significa que existe parcela da força de trabalho sendo subutilizada, segundo o marco teórico do Prealc.

Feitas estas considerações, é preciso deixar claro que o amadurecimento teórico das formulações iniciais sobre o setor informal consubstanciado nos trabalhos de Souza e de Tokman - e que servem de marco teórico para a análise dos dados reunidos para este artigo - destacam que, em uma economia subdesenvolvida, essas formas de manifestação da informalidade representam uma marca do processo de desenvolvimento capitalista, o que não exclui a possibilidade de que a dimensão absoluta e/ou relativa do setor informal possa se reduzir em momentos de crescimento contínuo da atividade econômica como um todo - algo, aliás, que ocorreu na economia brasileira, nos anos sujeitos à análise neste artigo. O que se deve analisar é se de fato toda e qualquer informalidade foi eliminada para, então, debruçar-se em uma afirmação que advogue a economia estar em pleno emprego. Ao rejeitar a noção de que a remuneração do trabalho esteja relacionada à produtividade marginal do mesmo, abre-se espaço para o conceito de subutilização do trabalho em contexto que mostre - como é o caso mais comum, especialmente em uma economia subdesenvolvida - que, mesmo em situações que denotem período relativamente longo de crescimento da atividade econômica, a demanda efetiva ainda não tenha sido suficiente para que o "fator trabalho" tenha sido de fato plena e adequadamente utilizado, dada a elevada heterogeneidade do setor não tipicamente capitalista da produção (Souza, 1980a; 1980b).

Assim, fica claro que, nos marcos teóricos mencionados, os movimentos da mão de obra entre diferentes setores dependem, fundamentalmente, da lógica da acumulação capitalista, e menos de decisões individuais por parte dos trabalhadores, embora não se deva excluir situações limites em que alguns podem “optar" por trocar uma renda futura (a ser recebida por meio da Previdência Social, por exemplo) pela maximização da renda presente ${ }^{11}$ ou simplesmente optem por atuar no setor informal

(11) Esta questão é bastante complexa. Os próprios trabalhos do Prealc e mesmo Souza definem, como uma das caraterísticas do setor informal, a maximização da renda presente, conforme Tokman (1987) e Souza (1980a e 1980b) salientam. Ademais, o amadurecimento dos estudos sobre setor informal mostra que não é pouco comum que algumas dessas atividades tenham renda superior à de atividades semelhantes exercidas no setor formal; tampouco se deve descartar que, em alguns casos, os trabalhadores conscientemente decidam permanecer nas atividades informais ao invés de migrarem para as formais, se tiverem essa oportunidade. Mas o fato que deve ser colocado como mais relevante é o de que, segundo a concepção dos autores do Prealc, a criação, recriação e remodelamento das atividades informais, bem como os movimentos de crescimento dos segmentos formais da atividade produtiva dependem da dinâmica da acumulação capitalista e dos termos em que se desdobra a concorrência intercapitalista. Para acesso a um estudo robusto que, entre outros temas importantes, discute escolhas individuais de trabalhadores entre atuar no setor formal ou no informal, adotando um marco teórico diferente ao que orienta a análise de dados neste artigo, ver: Barros et al. (1993). Também vale mencionar o estudo de Barros et al. (1990), que, utilizando também um marco teórico diferente ao adotado neste artigo, investigam a mobilidade de trabalhadores assalariados entre postos de trabalho do setor formal e do setor informal, descrevendo diferentes aspectos desses movimentos, mas atestando a elevada evidência dos mesmos. 
ao invés de buscar um assalariamento formal ${ }^{12}$ (com carteira assinada, no caso do Brasil, o símbolo da formalização do contrato de trabalho).

Para finalizar, vale destacar alguns comentários adicionais acerca dessa discussão sobre a intencionalidade ou a opção dos trabalhadores entre trabalhar em atividades formalizadas ou em atividades que poderiam ser consideradas como informais.

Estudo realizado por Ulyssea (2006), autor de vertente ideológica diferente à dos autores do Prealc, avalia diversos estudos sobre o tema e, em relação especificamente ao debate sobre segmentação do mercado de trabalho e à possibilidade de escolha individual, por parte do trabalhador, entre manter-se no setor informal ou migrar para uma situação mais estável no setor formal, o autor reconhece explicitamente que existe viva controvérsia sobre o tema. Ulyssea (2006) arrola estudos de Barros et al. (1993); Maloney (1999); Carneiro e Henley (2001); Tanuri-Pianto e Pianto (2002) e Soares (2004) $)^{13}$ para sustentar que não existe consenso sobre o assunto. De todo modo, fica aberta a possibilidade (referendada pela literatura especializada no tema) de que parcela relevante dos trabalhadores do setor informal estejam nesta situação por causa de falta de oportunidades no setor formal. Desta forma, podemos afirmar que a leitura também de autores de diferentes posições ideológicas em relação aos que foram tomados como referência teórica para a análise dos dados da economia brasileira neste artigo permite sustentar de forma mais robusta a ideia de que a ocupação no setor informal representa subutilização de mão de obra em um mercado de trabalho como o brasileiro.

Nas próximas seções, procederemos à análise dos dados.

\section{A mensuração do desemprego no Brasil}

\subsection{Aspectos gerais}

Se a primeira evidência de uma situação de pleno emprego é a constatação de uma baixa taxa de desemprego na economia, então, este deve ser o ponto de partida para qualquer discussão sobre o tema.

Partindo desta premissa, deve-se registrar, antes de mais nada, que ainda não existe no Brasil uma série histórica longa o suficiente que tenha base de comparação

(12) Barbosa (2009) mostra que as relações entre os setores formal e informal são redefinidas recorrentemente, e desde sempre não devem ser classificadas pela sua precariedade social. $\mathrm{O}$ autor argumenta que ainda nos anos mais recentes é possível haver precariedade mesmo dentro do setor formal - o que explicaria, no nosso entender, a possibilidade de um trabalhador optar pela inserção no setor informal, mesmo que tenha a oportunidade ou a possibilidade de inserir-se no chamado setor formal.

(13) Favor ver a citação completa nas referências bibliográficas mencionadas no próprio artigo. 
e que represente uma taxa de desemprego verdadeiramente nacional ${ }^{14}$, conforme ocorre na maior parte dos países desenvolvidos. De todo modo, uma eventual série histórica de uma taxa nacional de desemprego seria, na realidade, uma série revelando uma taxa média entre diferentes regiões, em um país com elevada desigualdade regional de desenvolvimento ${ }^{15}$ e diversos graus de urbanização em diferentes partes do território nacional.

A série histórica mais longa disponível divulgada pelo IBGE é a da Pesquisa Mensal de Emprego (PME), que se refere apenas às seis principais regiões metropolitanas do país e não capta a diversidade de situações ocupacionais existentes em todo o território nacional ${ }^{16}$.

De todo modo, a existência de uma média nacional não conseguiria sintetizar de maneira precisa a diversidade de situações de um país com duas metrópoles gigantescas, segundo padrões internacionais, diversas regiões metropolitanas altamente populosas e um expressivo número de municípios ${ }^{17}$. Muitos destes municípios são de pequeno porte e, frequentemente, sequer possuem um mercado de trabalho como tal, ou seja, como um espaço em que há um cotejamento entre a oferta de mão de obra e a demanda por força de trabalho exercida pelas empresas privadas, nos diferentes setores de atividade, e também pelas empresas públicas e o setor público de modo geral. Nestes casos, existem apenas espaços ocupacionais que reúnem atividades de subsistência (em setores agrícolas ou em atividades que envolvem a pequena produção mercantil) e uma ampla gama de tarefas exercidas informalmente. $\mathrm{Na}$ verdade, em todos os municípios (independentemente do seu tamanho) existe ampla parcela de informalidade na estrutura ocupacional.

A elevada desigualdade estrutural existente entre a realidade econômica das metrópoles e dos municípios do interior do Brasil muitas vezes promove resultados diferentes em termos de geração de postos de trabalho em cada caso. Tomando-se como exemplo o emprego formal medido pela $\mathrm{PME}^{18}$ e o medido pelo Ministério do

(14) Recentemente, o IBGE reconheceu a fragilidade da inexistência de uma taxa de amplitude nacional e passou a produzir a PNAD Contínua, com uma periodicidade maior (trimestral, contra a PNAD anual que a precede) e também maior abrangência territorial. Porém, como a pesquisa ainda é muito recente (apresenta dados apenas a partir do primeiro trimestre de 2012), naturalmente ainda não existe uma série histórica que permita uma base de comparação, razão pela qual este artigo ainda utiliza as informações da PME. Para conhecer a metodologia das PNADs Contínuas, ver: ftp://ftp.ibge.gov.br/Trabalho_e_Rendimento/Pesquisa_Nacional_por_Amostra_de_ Domicilios_continua/Fasciculos_Indicadores_IBGE/pnadc_201404_trimestre_caderno.pdf.

(15) Essa elevada desigualdade regional é um dos principais aspectos contemplados no conceito de heterogeneidade estrutural definido por Pinto (1979), para retratar a realidade de economias subdesenvolvidas.

(16) As taxas de desemprego calculadas pelo Dieese, em convênio com diferentes instituições estaduais, padecem do mesmo problema das taxas calculadas pela PME (embora tenham conteúdos metodológicos diferentes), uma vez que se referem apenas a algumas das principais regiões metropolitanas do país.

(17) E, ainda mais, com a elevada desigualdade regional acima aludida.

(18) Que, como vimos, considera apenas as seis maiores regiões metropolitanas do Brasil. 
Trabalho, a partir dos dados da Rais ${ }^{19}$, nota-se que a taxa de crescimento do emprego com carteira, ao longo do período 2007-2010, período em que foi mais expressivo o crescimento do número de postos de trabalho no Brasil, foi um pouco maior no Brasil como um todo (dados da Rais) do que nas seis regiões metropolitanas cobertas pela pesquisa do IBGE, espelhando um crescimento maior, em média, do emprego em municípios de menor porte (Tabela 1).

Tabela 1

Brasil - Pessoal Ocupado Com carteira

(em 1.000 pessoas)

\begin{tabular}{c|c|c}
\hline & PME $^{1}$ & RAIS $^{2}$ \\
\hline 2007 & 9,937 & 37,607 \\
\hline 2008 & 10,574 & 39,441 \\
\hline 2009 & 10,749 & 41,207 \\
\hline 2010 & 11,594 & 44,068 \\
\hline Variação no período & 16.7 & 17.2 \\
\hline
\end{tabular}

${ }^{1}$ Referente a 6 regiões metropolitanas.

${ }^{2}$ Referente a 27 UFs.

* Dados referentes a outubro

Fonte: IBGE e TEM. Elaboração: Ipea/Dimac/GAP.

Além das desigualdades regionais (e de tamanhos de municípios) mencionadas acima, deve-se também destacar, desde logo, quando se pretende avaliar uma suposta situação de pleno emprego em uma economia como a brasileira, a presença de diversas formas de inserção no mercado de trabalho brasileiro que evidenciam elevada informalidade das ocupações.

A Tabela 2 revela que ainda existe uma parcela expressiva das ocupações que se encontra na informalidade, embora esta parcela esteja em declínio nos últimos $\operatorname{anos}^{20}$. As ocupações classificadas como informais na Tabela 2 referem-se aos empregados assalariados sem registro em carteira, a todos os trabalhadores domésticos (registrados ou não), a quem trabalha por conta própria (em muitos estudos sobre mercado de trabalho também são denominados trabalhadores

(19) Que inclui todos os municípios brasileiros.

(20) A tabela não explicita os resultados de 2011 e de 2012 em razão do fato de que, depois do Censo de 2000, foram utilizados novos valores para expansão da amostra dos dados das Pnads, comprometendo a comparação entre os dados anteriores e os posteriores ao mais recente Censo. De todo modo, os dados da tabela são suficientes para revelar que existe uma parcela significativa do total dos trabalhadores ocupados que ainda atua em situações de informalidade dentro do mercado de trabalho. O peso relativo do setor informal diminuiu ao longo do período em tela, mas ainda é alto. A elevada presença do setor informal é uma das mais marcantes características estruturais do mercado de trabalho brasileiro e este é um fato importante a ser ressaltado no argumento central que será desenvolvido neste artigo, conforme será visto na sequência do mesmo. Sobre o comportamento do mercado de trabalho nas últimas décadas do século XX, ver: Baltar (2003; 2006). 
autônomos) e também aos ocupados sem rendimentos (que ainda representavam, em 2009 , quase $2 \%$ do total de ocupados do mercado de trabalho brasileiro). Tratam-se de trabalhadores(as) que estão excluídos dos benefícios sociais, trabalhistas e previdenciários e/ou que revelam uma situação em que não se encontram de fato empregados (ou seja, trabalhando de forma assalariada), mas exercendo atividades que representam estratégias de sobrevivência e que estão ainda disponíveis para serem exploradas pelo capital, nem que seja em funções que exijam baixa qualificação da mão de obra.

Tabela 2

Indicadores selecionados do mercado de trabalho, Brasil (2002-2009)

Em percentual

\begin{tabular}{|c|c|c|c|c|c|}
\hline Indicadores/Ano & 2002 & 2004 & 2006 & 2008 & 2009 \\
\hline $\mathrm{PEA}^{1}$ & 100,0 & 100,0 & 100,0 & 100,0 & 100,0 \\
\hline Ocupados $^{2}$ & 88,4 & 88,7 & 89,6 & 91,3 & 90,0 \\
\hline Desempregados & 11,4 & 11,1 & 10,3 & 8,6 & 9,9 \\
\hline Total de Empregados & 54,6 & 56,0 & 57,0 & 59,8 & 58,4 \\
\hline Empregados do setor privado formal & 28,7 & 30,4 & 31,7 & 34,3 & 34,3 \\
\hline Militares e funcionários públicos 3 & 9,9 & 9,8 & 9,8 & 10,1 & 10,0 \\
\hline Empregadores & 4,2 & 4,0 & 4,5 & 4,6 & 4,3 \\
\hline Total da Ocupação Formal & 42,9 & 44,2 & 45,9 & 49,0 & 48,7 \\
\hline Empregados sem registro & 16,0 & 15,9 & 15,5 & 15,4 & 14,0 \\
\hline Trabalhadores domésticos & 8,3 & 8,3 & 8,1 & 7,6 & 8,1 \\
\hline Trabalhadores por conta própria & 18,8 & 18,4 & 18,0 & 17,4 & 17,4 \\
\hline Não remunerados & 2,4 & 2,0 & 2,0 & 1,9 & 1,8 \\
\hline Total da Ocupação Precária & 45,5 & 44,6 & 43,7 & 42,3 & 41,3 \\
\hline
\end{tabular}

1) Trabalhadores ocupados com 10 anos ou mais de idade no trabalho principal da semana de referência;

2) Exclusive trabalhadores para próprio uso;

3) Inclusive celetistas que atuam no setor público.

Fonte: PNADs/IBGE. Elaboração própria.

Essa elevada informalidade embute diversas situações ocupacionais cuja principal característica é a alternância entre situações de ocupação precária e de desemprego disfarçado, quando não de momentos de saída temporária do mercado de trabalho, fazendo oscilar a taxa de participação da PEA em relação à PIA (Troyano, 1991). Nesse sentido, a comparação entre as taxas de desemprego aberto com as taxas de desemprego mais amplas, que descrevam as situações de inserção 
precária nos mercados de trabalho regionais ${ }^{21}$, revela uma diferença não desprezível em seus resultados, embora ambas exibam uma trajetória declinante no período analisado neste artigo. Ou seja, a taxa de desemprego aberto para os respectivos mercados de trabalho das metrópoles (bem como o valor conjunto de todas elas, conforme divulgado pela PME) atingiu de fato patamares bastante baixos no período analisado neste artigo. Este patamar pode ser considerado baixo tanto para padrões internacionais ou mesmo quando se compara sua trajetória no mercado de trabalho brasileiro com seus valores históricos. Porém, em um mercado de trabalho como o brasileiro, a realidade sobre o desemprego não se expressa totalmente pelos indicadores de desemprego aberto (Troyano, 1988), sendo bastante expressivas as situações de desemprego oculto pelo trabalho precário ou pelo desalento, que representam, na verdade, formas de "desemprego disfarçado", conforme indica a literatura internacional ${ }^{22}$.

(21) Como, por exemplo, as taxas de desemprego calculadas pelo Dieese, nas diversas metrópoles. Estas taxas, devido à metodologia adotada para medi-las, consideram como desempregado um contingente mais amplo de situações que, pelas taxas de desemprego aberto divulgadas pelo IBGE, poderiam ser enquadradas em situações extremas (ou como ocupados ou então como inativos). Na metodologia do Dieese, as situações de desemprego são também classificadas como desemprego oculto pelo trabalho precário ou oculto pelo desalento, sendo divulgadas à parte da taxa de desemprego aberto. No caso da metodologia da PME (Pesquisa Mensal de Emprego), do IBGE, tanto a definição de ocupação quanto a de desocupação (e, por consequência, a de inatividade) tendem a subestimar a taxa de desemprego, se a mesma for comparada à taxa de desemprego total (ou seja, aquela dada pela soma de desemprego oculto mais desemprego aberto) da PED. No caso do IBGE, "são classificadas como ocupadas na semana de referência as pessoas que exerceram trabalho remunerado ou sem remuneração, durante pelo menos uma hora completa na semana de referência, ou que tinham trabalho remunerado do qual estavam temporariamente afastadas nessa semana". Também na PME, "são classificadas como desocupadas na semana de referência as pessoas sem trabalho na semana de referência, mas que estavam disponíveis para assumir um trabalho nessa semana e que tomaram alguma providência efetiva para conseguir trabalho no período de referência de 30 dias, sem terem tido qualquer trabalho ou após terem saído do último trabalho que tiveram nesse período". Existe também a situação classificada para um período de 30 dias, mas, como se pôde perceber, independentemente do período em questão (embora isso também seja uma questão importante, quando se comparam resultados), a definição de ocupação é bem mais ampla no caso da PME do que a definida pela PED, pois mesmo situações esporádicas de trabalho no período de referência definem o trabalhador, na PME, como ocupado, não existindo uma definição intermediária entre o desemprego aberto (desocupação, na PME) e ocupação. Essa metodologia do IBGE sem dúvida tem respaldo inclusive na literatura internacional (Sorrentino, 1993; 1995) sobre o tema e capta de forma rigorosa as situações de desemprego aberto no Brasil; porém, peca por não avaliar as situações "intermediárias" ou de "transição" entre a ocupação estável e o desemprego aberto, que nas PEDs são definidas como desemprego oculto (pelo trabalho precário ou pelo desalento). E estas situações, em mercados de trabalho de economias subdesenvolvidas, são muito habituais. No IBGE também é avaliada a situação de desalento, mas a mesma acaba sendo incluída entre as pessoas que se encontram na situação de inatividade, enquanto que nas PEDs, dependendo da resposta do pesquisado sobre o tempo em que se encontra na situação de desalento, a pessoa pode ser incluída nos dados de desemprego oculto pelo desalento. Esta distinção entre as modalidades de medida do desalento explica a subestimação da situação de desemprego quando a mesma é medida pelo IBGE, em comparação com a situação medida pelas PEDs. Para mais detalhes, ver: IBGE. Série Relatórios Metodológicos. Pesquisa Mensal e Emprego (PME - 23), 2. ed. Ver também Montagner e Brandão (1996), que discutem estas questões metodológicas.

(22) Sorrentino (1995) destaca que, nos EUA, o Bureau of Labour define e calcula sete tipos diferentes de taxas de desemprego, sendo que o terceiro tipo (U3, na denominação do Censo americano) é aquele tido como a taxa de desemprego oficial, sendo que as demais taxas de desemprego em seguida incluem situações ocupacionais crescentemente mais amplas, que poderiam ser classificadas como "disguised unemployment", ou seja, desemprego disfarçado. 
No caso brasileiro, a metodologia que procura captar essas formas mais heterogêneas de inserção no mercado de trabalho brasileiro originou-se na Pesquisa do Emprego e do Desemprego (PED), desenvolvida inicialmente (em 1984) na região metropolitana de São Paulo, em convênio entre o DIEESE e a Fundação SEADE, sendo posteriormente utilizada para medir as taxas de desemprego em diversas outras regiões metropolitanas brasileiras (Troyano, 1990).

As taxas de desemprego pesquisadas pela PED-Dieese, em várias regiões metropolitanas brasileiras, classificam o desemprego total como uma soma entre o desemprego aberto $^{23}$ e o desemprego oculto ${ }^{24}$, o qual, por sua vez, se divide entre o desemprego oculto pelo trabalho precário e o desemprego oculto pelo desalento. Em todas as regiões metropolitanas pesquisadas com a metodologia da PED, houve redução de todas as modalidades da taxa de desemprego entre o início dos anos 2000 e os dados de dezembro de $2012^{25}$, mas ainda persistem elevadas parcelas da mão de obra em condições precárias de ocupação, mas que, na metodologia da PME, por exemplo, seriam (pelo menos em parte) classificadas como inativas, sendo retiradas das estatísticas de desemprego ${ }^{26}$.

É justamente por incorporar, em suas medidas, componentes de desemprego "disfarçado" e por relatar mais fielmente a acentuada heterogeneidade estrutural do mercado de trabalho brasileiro, bem como suas diversidades regionais, que se deve considerar mais adequado discutir o suposto pleno emprego no Brasil tomando-se por base a evolução das taxas de desemprego total (ou seja, o desemprego aberto mais o desemprego oculto) das PEDs metropolitanas conduzidas em convênios com o Dieese, ao invés de levar em conta a taxa de desemprego aberto da própria PED ou a taxa de desemprego aberto da PME, mesmo depois das mudanças de metodologia promovidas pelo IBGE (e colocadas em prática a partir dos dados divulgados em março de $2002^{27}$ ).

(23) Pelos critérios da PED, o desemprego aberto é definido pela "proporção de pessoas que procuraram trabalho de maneira efetiva nos últimos 30 anos anteriores ao dia da entrevista e não exerceram nenhum trabalho nos últimos 7 dias".

(24) O desemprego oculto se divide, segundo as definições da PED, entre o oculto pelo trabalho precário e o oculto pelo desalento. O oculto pelo trabalho precário reúne a "proporção de pessoas que realizaram algum trabalho eventual de auto-ocupação, ou seja, sem qualquer perspectiva de continuidade e previsibilidade, ou realizam trabalho não remunerado em ajuda de negócios de parentes e que procuraram mudar de trabalho nos 30 dias anteriores ao da entrevista ou que, não tendo procurado trabalho neste período, o fizeram sem êxito até 12 meses atrás". Já os desempregados ocultos pelo desalento são aqueles classificados como a "proporção de pessoas que não possuem trabalho e nem procuraram nos últimos 30 dias, por desestímulo do mercado de trabalho ou por circunstâncias fortuitas, mas apresentaram procura efetiva de trabalho nos últimos 12 meses”. Ver, para maiores detalhes: Fundação Seade (1988).

(25) Que é o mês que encerra o período em análise neste artigo.

(26) Ver segunda edição de IBGE: Série Relatórios Metodológicos. Pesquisa Mensal e Emprego (PME 23) e comparar com Fundação Seade (1998).

(27) Ver: IBGE. Série Relatórios Metodológicos. Pesquisa Mensal e Emprego (PME - 23), 2. ed. 
Os dados da Tabela 3 destacam a contribuição do desemprego oculto (em suas duas modalidades) para o desemprego total, o que permite avaliar o ainda presente elevado grau de subutilização do trabalho nas Regiões Metropolitanas em que estes dados são coletados.

Na região metropolitana $(\mathrm{RM})$ de Salvador, por exemplo, a taxa de desemprego aberto, em dezembro de 2012, era igual a 11,4\% da PEA, mas, considerando-se o desemprego oculto, a taxa de desemprego total saltava para 16,6\% (resultado de 3,4\% em situação de desemprego oculto pelo trabalho precário e mais 1,8\% em desemprego oculto pelo desalento); da mesma forma, na RM de Recife, também em dezembro de 2012, o desemprego aberto era igual a 7,8\% e o total igual a $12,2 \%$. Ou seja, muitas vezes, a situação de desemprego oculto pode representar até mais do que $50 \%$ do aberto, como na RM de Recife ou, pelo menos, algo próximo de $50 \%$ do aberto, como no caso da RM de Salvador, ou cerca de 30\%, como nas Regiões Metropolitanas do Distrito Federal e na de Fortaleza, ou um quarto, como na de São Paulo. Portanto, tomar a taxa de desemprego aberto (quer seja na metodologia do IBGE ou na das PEDs) como indicador para afirmar que a economia brasileira se encontra em pleno emprego representa um equívoco sob diversos pontos de vista, inclusive pelo fato de que o mercado de trabalho brasileiro tem acentuada diversidade regional.

Tabela 3

PEDs - Regiões Metropolitanas

Taxa de desemprego (em dezembro de 2012)

\begin{tabular}{cccc}
\hline & Aberto & Oculto & Total \\
\hline São Paulo & 8.7 & 2.2 & 10.9 \\
Recife & 7.8 & 4.4 & 12.2 \\
Porto Alegre & 5.6 & 0.9 & 6.5 \\
Belo Horizonte & 4.9 & 0.4 & 5.3 \\
Distrito Federal & 8.5 & 2.6 & 11.1 \\
Salvador & 11.4 & 5.2 & 16.6 \\
Fortaleza & 5.9 & 1.8 & 7.7 \\
\hline
\end{tabular}

Fonte: PEDs das respectivas RMs. Elaboração própria.

Sendo assim, dependendo do indicador de desemprego utilizado, pode-se muitas vezes chegar a uma conclusão metodologicamente precária - baseada em avaliações tão simplórias quanto errôneas - de que em alguns momentos de ascensão um pouco mais prolongada do ciclo econômico, a economia brasileira ${ }^{28}$ estaria $^{2}$ operando em uma situação de pleno emprego.

(28) Alguns analistas assim afirmam, generalizando a afirmação para o conjunto da economia nacional. 


\subsection{A heterogeneidade do mercado de trabalho brasileiro}

A herança do subdesenvolvimento gerou no Brasil um mercado de trabalho marcado por forte heterogeneidade estrutural (Barbosa de Oliveira, 1988), no qual convivem empresas com diferentes níveis de produtividade e diversos graus de desenvolvimento tecnológico, existindo expressivo contingente de mão de obra que atua na informalidade, tanto nas metrópoles, como também nas cidades médias e pequenas. Essa elevada heterogeneidade estrutural se reflete também em significativa diversidade da estrutura ocupacional, comportando formas de inserção ocupacional bastante heterogêneas do ponto de vista da regularidade do trabalho exercida pelo trabalhador ao longo de sua vida profissional, como também do ponto de vista da regularidade da jornada de trabalho, e ainda no que se refere à estabilidade no emprego ou à regularidade e previsibilidade dos rendimentos recebidos, bem como da dedicação do trabalhador à carreira (ou ao ofício) e, finalmente, também segundo o seu usufruto de direitos trabalhistas e sociais - inclusive previdenciário. Essas formas precárias de inserção no mercado de trabalho muitas vezes evidenciam situações em que o trabalhador está em condição mais próxima do desemprego aberto (situação mais habitualmente definida como forma de medição do complexo fenômeno do desemprego) do que de uma ocupação estável de fato.

É preciso também sublinhar que a diversidade de situações que marcam o mercado de trabalho de um país com as características do Brasil favorece uma elevada oscilação na proporção da população em idade ativa que de fato é classificada como economicamente ativa - situação descrita pelas chamadas "taxas de atividade" ou "taxa de participação da PEA".

Um estudo sobre pleno emprego em um país com um mercado de trabalho com estas características deveria também investigar os fatores que promovem as movimentações da população em idade ativa entre as situações de inatividade e as de participação no mercado de trabalho (ou seja, contabilizadas como pertencentes à PEA - população economicamente ativa ${ }^{29}$. Estas oscilações entre diferentes situações ocupacionais representam, conforme mostrou a literatura do Prealc, uma marca dos mercados de trabalho de países de desenvolvimento tardio, como o Brasil. Teoricamente, isso foi diagnosticado pela investigação que os autores ligados ao PREALC fizeram acerca dos efeitos das mudanças ocorridas no setor formal da atividade econômica sobre o espaço econômico do setor informal (Souza, 1980b).

De acordo com o Gráfico 1 a seguir, nota-se que a taxa de participação (PEA/PIA) oscilou bastante nos anos finais do período em análise, especialmente por causa do comportamento instável da PEA. Esta situação peculiar, descrita pelas características da trajetória da PEA e da taxa de participação brasileira, difere da de países desenvolvidos, nos quais os mercados de trabalho são mais homogêneos e

(29) Um estudo pioneiro sobre o tema foi apresentado por Dedecca e Ferreira (1989). 
onde um indicador síntese de desemprego nacional expressa de forma razoavelmente consistente a situação ocupacional média da maioria daqueles países.

No mercado de trabalho brasileiro existe um elevado contingente de pessoas que alterna momentos de inserção no mercado de trabalho (quer seja como ocupados - muitas vezes em situações precárias, do ponto de vista da execução de algum tipo de trabalho, bem como da irregularidade e da instabilidade da remuneração - ou como desempregados) com momentos de inatividade. A inatividade deve-se a decisões relacionadas a uma avaliação de que teria dificuldade de encontrar trabalho naquele momento ou naquela região, ou por circunstâncias pessoais (como, por exemplo, doença em família ou dificuldades de locomoção relacionadas a fatores logísticos da região em que habita ou também por enfermidade ${ }^{30}$. A própria existência desse fenômeno das oscilações das taxas de participação revela a situação estrutural de potencial subutilização da capacidade laborativa de parcela do contingente da PEA (População Economicamente Ativa).

\section{Gráfico 1}

Taxa de atividade e diferença absoluta entre população em idade ativa (PIA) e população economicamente ativa (PEA) de janeiro de 2007 a janeiro de 2013


Fonte: IBGE (2013). Elaboração própria.

(30) Estas situações variam segundo uma enorme variedade de fatores, um dos quais sem dúvida é a oscilação do ciclo econômico, de tal forma que a situação conjuntural da economia afeta de forma distinta as diferentes famílias e os vários membros de cada uma delas. As fragilidades do sistema de previdência, os baixos rendimentos do mercado de trabalho em geral e própria precariedade do mesmo, muitas vezes não exibindo dinamismo suficiente para ofertar empregos formais a todos os que precisam trabalhar, faz oscilar a frequência com que os diferentes membros das famílias decidem ou não participar da PEA. Tanto nas fases de alta do ciclo, quanto nas fases de baixa, existem motivos para que algumas pessoas procurem um emprego ou uma auto-ocupação como forma de complementar a renda familiar. Para mais detalhes sobre o comportamento da taxa de participação, ver: Dedecca e Ferreira (1989) e também Dedecca (1996). 


\section{A evolução do Mercado de Trabalho no Brasil entre 2003 e 2013}

O objetivo desta seção é reforçar algumas evidências já apontadas na seção empírica anterior. Os dados desta seção foram organizados de tal forma a permitir uma compreensão da evolução dos indicadores de mercado de trabalho brasileiro e, em especial, uma avaliação sobre a suposta situação de pleno emprego tendo por base as formulações teóricas mostradas nas duas primeiras seções do artigo. Para tanto, esta seção divide-se em três subseções. Na primeira delas é apresentado um exercício econométrico para averiguar a relação entre trajetória do PIB e trajetória da ocupação, para o período que se inicia em janeiro de 2003 e que termina em janeiro de 2013. Na segunda subseção, são discutidos os desempenhos dos indicadores que afetam a trajetória da taxa de desemprego, ressaltando também elementos que simbolizam uma subutilização do fator trabalho, segundo definido pela interpretação keynesiana e também pelas formulações do PREALC; na última subseção, são destacados elementos da trajetória da composição do emprego formal no Brasil desde 2003, chamando atenção para a heterogeneidade regional existente no mercado de trabalho brasileiro.

\subsection{A relação crescimento e ocupação}

Ao longo dos últimos anos, o mercado de trabalho brasileiro vem mostrando de forma contínua um bom desempenho. De acordo com a Pesquisa Mensal de Emprego (PME) divulgada pelo IBGE, a população ocupada nas seis regiões metropolitanas do país ${ }^{31}$ cobertas pela pesquisa saltou de 17,6 milhões em julho de 2002 para 23,4 milhões em dezembro de 2012, o que corresponde a um aumento da ordem de $33 \%$ no período.

Esta expansão da população ocupada no país ocorreu concomitantemente com uma trajetória de crescimento do PIB (entre 2003 e 2012) que superou a trajetória em períodos anteriores, estimulando a hipótese de que o grande propulsor do emprego no país foi o crescimento da economia.

Com base nessas suspeitas, foi estimada, nesta subseção, uma equação com o intuito de verificar econometricamente se há uma relação entre o emprego e o crescimento econômico do Produto Interno Bruto (PIB). O modelo teórico utilizado para o propósito seguiu o Princípio da Demanda Efetiva, expressa na função emprego de Keynes, que pressupõe a quantidade de emprego determinada pela demanda efetiva em unidades de salário. A função de emprego paramétrica segue a especificação da equação (1).

(31) Regiões Metropolitanas de Belo Horizonte, Porto Alegre, Recife, Rio de Janeiro, Salvador e São Paulo. 


$$
N_{r}=F_{r}\left(D_{w}\right)
$$

Supondo que cada montante de demanda efetiva total corresponda a um valor $D_{w}$ em unidades salariais, a função emprego generaliza que $N_{r}$ homens estarão empregados na indústria $r$ quando a demanda efetiva for $D_{w}$. Essa função satisfaz ainda o principio da aditividade das funções individuais de emprego, em que a soma das funções de emprego das indústrias individuais $N=\sum N_{r}=\sum F_{r}\left(D_{w}\right)$ corresponde à função de emprego da indústria agregada (Keynes, 1988).

Desse modo, baseado no modelo teórico da função emprego de Keynes, foi formulado o modelo econométrico, cuja melhor especificação correspondeu ao logaritmo (log) do emprego em relação ao logaritmo do PIB. O coeficiente dessa relação funcional representaria a sensibilidade do emprego em relação ao PIB. Além disso, devido ao comportamento sazonal das series mensais utilizadas, foi empregado o método de variáveis dummies para correção. Pelo teorema FrischWalgh o uso de dummy para dessazonalização de séries temporais controla o efeito sazonal da variável explicada e explicativa ao mesmo tempo. Por essa razão, a especificação funcional do modelo econométrico foi definida conforme expresso pela equação (2).

$$
\log N_{t}\left(Y_{t}, D_{m}\right)=\beta_{0}+\beta_{1} \log Y_{t}+\beta_{1+m-1} D_{m-1}+u_{t} \quad \operatorname{com} u_{t} \sim\left(0, \sigma^{2}\right)
$$

Em que $\log N_{t}$ representa o logaritmo do número de pessoas ocupadas em empregos formais da economia no tempo e $\log Y_{t}$ o logaritmo do nível de produto definido segundo o principio da demanda efetiva no tempo. O subscrito temporal $t$ variou de janeiro de 2003 a janeiro de 2013. A variável $D_{m-1}$ ilustra o conjunto de variáveis dummy do componente sazonal, menos a dummy de referência. Portanto, como as observações foram mensais, haverá 11 variáveis dummies contra uma dummy de referência. $\mathrm{O}$ termo de erro $u_{t}$ segue uma distribuição normal, com média zero e variância constante $\sigma^{2}$, expressando que na média o emprego seja explicado apenas pelo crescimento econômico e alterações sazonais (Gujarati; Porter, 2011).

As séries temporais em logaritmo de emprego e PIB, utilizadas na pesquisa, foram identificadas pelo teste Dickey-Fuller aumentado como integradas de ordem um [I(1)]. Por essa razão foram corrigidas pelo método de primeira diferença, perdendo a primeira observação e captando a relação de curto prazo entre as variáveis. Desse modo, o modelo econométrico assumiu a forma final da estimativa em que o crescimento da população ocupada é explicado pelo crescimento da produção agregada, como segue na equação (3). 
$d \log N_{t}=\hat{\alpha}_{0}+\hat{\alpha}_{1} d \log Y_{t}+\hat{\alpha}_{1+m-1 t} D_{m-1}+\hat{\varepsilon}_{t} \operatorname{com} \varepsilon_{t} \sim\left(0, \sigma^{2}\right)$

Sendo $d \log N_{t}$ o crescimento da população ocupada, $d \log Y_{t}$ o crescimento da Produção Interna Bruta (PIB) e $\hat{\varepsilon}_{t}$ uma estimativa do distúrbio aleatório com as mesmas propriedades de média zero e variância constante. Os parâmetros $\hat{\alpha}$ representam as estimativas das relações funcionais, cujo significado de $\hat{\alpha}_{1}$ expressa a elasticidade do emprego em relação ao PIB. Entre os resultados possíveis dessas relações estariam uma função emprego positiva, ou neutra em relação ao crescimento econômico. A função emprego será positiva se houver significância estatística do parâmetro estimado $\hat{\alpha}_{1}$, e será neutra caso o referido parâmetro não tenha significância estatística.

Para estimar o efeito do crescimento econômico sobre o crescimento da ocupação foi utilizado o método de Mínimos Quadrados Ordinário (MQO). Esse exercício permitiu medir o efeito de curto prazo do crescimento econômico sobre a geração de empregos no país. As variáveis utilizadas como proxies do crescimento do emprego e do crescimento econômico foram o número de pessoas com dez anos ou mais de idade ocupadas na semana de referência (em mil pessoas) e o Produto Interno Bruto (PIB) brasileiro deflacionado pelo Índice Geral de Preços - Deflator Implícito (IGP-DI) a preços de janeiro de 2013 (em milhões de Reais).

A base de dados da pesquisa foi construída a partir dos bancos de dados da pesquisa mensal do emprego (PME) do Instituto Brasileiro de Geografia e Estatística (IBGE) e do Instituto de Pesquisa Econômica (IPEA) para as variáveis de crescimento do emprego e crescimento econômico, respectivamente. As séries utilizadas compreendem o período de janeiro de 2003 a janeiro de 2013. A escolha de 2003 como início da série estudada justifica-se pelo fato de que no último trimestre de 2003 a economia brasileira já apontava para uma trajetória de crescimento que se diferenciava com o que havia ocorrido em anos imediatamente anteriores; janeiro de 2013 representa o último dado disponível quando da elaboração deste estudo. A escolha desse dado para o final do período também se justifica pelo fato de que, ainda no final de 2012, havia estudiosos da realidade laboral e econômica brasileira afirmando que o mercado de trabalho nacional estaria em pleno emprego. 
Tabela 4

Evidência empírica da função emprego no Brasil, com estimativa robusta dos parâmetros segundo o método Newey-West, de janeiro de 2003 a janeiro de 2013

\begin{tabular}{|c|c|c|c|c|}
\hline Variáveis explicativas & Coeficientes & Erro-Padrão & Estatística t & Probabilidade \\
\hline Constante & -0.01097 & 0.001884 & -5.82393 & 0.0000 \\
\hline Crescimento do PIB & 0.037778 & 0.015253 & 2.476701 & 0.0148 \\
\hline D2 & 0.010558 & 0.002000 & 5.279896 & 0.0000 \\
\hline D3 & 0.012361 & 0.002530 & 4.885057 & 0.0000 \\
\hline D4 & 0.011858 & 0.002223 & 5.334694 & 0.0000 \\
\hline D5 & 0.014895 & 0.002774 & 5.370463 & 0.0000 \\
\hline D6 & 0.014392 & 0.002857 & 5.037761 & 0.0000 \\
\hline D7 & 0.014074 & 0.002286 & 6.157746 & 0.0000 \\
\hline D8 & 0.017003 & 0.002160 & 7.871459 & 0.0000 \\
\hline D9 & 0.019632 & 0.002063 & 9.517203 & 0.0000 \\
\hline D10 & 0.011011 & 0.002503 & 4.398324 & 0.0000 \\
\hline D11 & 0.014547 & 0.002398 & 6.065239 & 0.0000 \\
\hline D12 & 0.012996 & 0.002255 & 5.763407 & 0.0000 \\
\hline \multicolumn{2}{|l|}{ Sumário de estatísticas } & Estatísticas & & Probabilidade \\
\hline \multicolumn{2}{|l|}{ Estatística $F$} & 16.79398 & & 0.000000 \\
\hline \multicolumn{2}{|l|}{$R^{\wedge} 2$} & 0.653192 & & \\
\hline \multicolumn{2}{|l|}{$R^{\wedge} 2$ ajustado } & 0.614297 & & \\
\hline \multicolumn{2}{|l|}{ Durbin-Watson } & 2.242664 & & \\
\hline \multicolumn{2}{|l|}{ Jarque Bera } & 0.694971 & & 0.706462 \\
\hline \multicolumn{2}{|l|}{ Breusch-Godfrey } & 0.819512 & & 0.443400 \\
\hline \multicolumn{2}{|l|}{ White } & 2.183842 & & 0.004100 \\
\hline \multicolumn{2}{|c|}{ Chow Breakpoint Test mês 01} & 0.990063 & & 0.467100 \\
\hline \multicolumn{2}{|c|}{ Chow Breakpoint Test mês 02} & 1.175024 & & 0.309800 \\
\hline
\end{tabular}

Fonte: Estimado pelos autores com base nos dados do IBGE e Ipea.

Após a estimação foram realizados os testes de Jarque Bera para normalidade dos resíduos, Breusch-Godfrey para autocorrelação serial e heterocedasticidade de White, além da estimativa robusta dos parâmetros pelo método Newey-West. Para verificar possíveis quebras estruturais, foi utilizada a estimativa recursiva do teste One-Step forecast e o teste de estabilidade Chow nos primeiros meses de 2009 para verificar quebras pontuais da crise financeira de 2008 . Foram empregados também os testes $t$ de Student e $F$ de Fisher para verificação da significância individual e conjunta dos parâmetros estimados, respectivamente (Gujarati; Porter, 2011). Todos os resultados das estimativas e testes podem ser observados na Tabela 4. 
A equação explicitada na Tabela 4 explica que o crescimento do emprego é uma função positiva do crescimento econômico. Significa dizer que, na média, a taxa de crescimento mensal do número de pessoas com dez anos ou mais empregadas na semana de referência no Brasil cresceu $\left(\frac{\partial\left(d \log N_{t}\right)}{\partial\left(d \log Y_{t}\right)}=\hat{\alpha}_{1}>0\right)$ por causa do crescimento mensal do PIB nacional. O coeficiente da variável de crescimento do $\operatorname{PIB}\left(\hat{\alpha}_{1}\right)$ teve significância estatística de $5 \%$.

A equação mostra que se tivesse ocorrido crescimento econômico zero, teria havido uma queda do desemprego da ordem de $0.01097 \%$. Mostra também que o acréscimo de $1 \%$ no crescimento da produção nacional promoveria, na média, uma expansão aproximada de $0.037778 \%$ no crescimento da população ocupada. Ambas as simulações estão desprezando os efeitos sazonais. Como simulação do crescimento econômico necessário para a manutenção da taxa de emprego, estimase que seria necessário um crescimento do PIB da ordem de 0.290381\%, desprezando o componente sazonal. Esse resultado é encontrado pelo zero da função a partir dos parâmetros estimados $\left(\hat{\alpha}_{o} e \hat{\alpha}_{1}\right)$.

As variáveis dummies de D2 até D12 representam os componentes sazonais em relação ao mês de janeiro (D1). Os coeficientes estimados para as referidas variáveis explicam que o crescimento mensal do número de pessoas ocupadas aumenta nos meses de fevereiro a dezembro em relação a janeiro. Todos os coeficientes estimados foram significativos a $1 \%$. As variáveis de crescimento do PIB e Dummy em conjunto são relevantes para explicar o crescimento do emprego com significância de $1 \%$, de acordo com o teste $F$ (Tabela 4 ).

O R quadrado, indicador de ajuste do modelo, informa que $65,31 \%$ do crescimento do emprego é explicado pelo crescimento econômico e pela sazonalidade mensal do emprego. Os demais resultados descrevem uma equação de características estatísticas desejáveis, com distribuição normal dos resíduos como sugere o teste Jarque Bera, com estatística 0.694971, significativa a 10\%; e ausência de autocorrelação serial conforme o teste Breusch-Godfrey para pequenas amostras com estatística 0.819512 , significativa a $10 \%$. O teste de heterocedasticidade de White para pequenas amostras rejeitou a hipótese de homocedasticidade até a $1 \%$, com estatística 2.183842. Mesmo assim, como a equação foi estimada com o desvio padrão robusto Newey-West, foram suprimidas as limitações estatísticas da heterocedasticidade e da autocorrelação residual, caso existisse.

Segundo a análise de quebra estrutural, pelo teste recursivo One-Step forecast, não foram identificadas quebras estruturais significativas para o período (Gráfico 2). Para confirmar esse resultado, foi estimado o teste Chow para pequenas 
amostras nos dois primeiros meses de 2009, logo após a crise financeira dos Estados Unidos de 2008. O teste não rejeitou a hipótese de ausência de quebra nos dois referidos meses, com estatísticas de 0.9900631 e 1.175024 , respectivamente, significativas a $10 \%$.

Gráfico 2

Teste recursivo One-Step forecast para análise de quebra estrutural do período



\subsection{A trajetória dos indicadores de emprego e de desemprego}

O resultado explicitado no Gráfico 3 (abaixo) fortalece a relação causal do crescimento econômico sobre o emprego descrita pela equação apresentada na Tabela 4 por compreender um período contido no intervalo de tempo da equação. A convergência entre as taxas de crescimento da população ocupada e população economicamente ativa, no momento de crescimento do emprego, expressa o efeito da produção econômica sobre a formalização do emprego. Além disso, o crescimento do emprego manteve-se superior ao crescimento da população em idade ativa em todo o período, especialmente quando verificadas as maiores taxas de crescimento do emprego, ocorridas de agosto a dezembro de 2012. 


\section{Gráfico 3}

Variação percentual interanual da população em idade ativa (PIA), população economicamente ativa (PEA) e população ocupada (PO) de janeiro de 2010 a janeiro de 2012

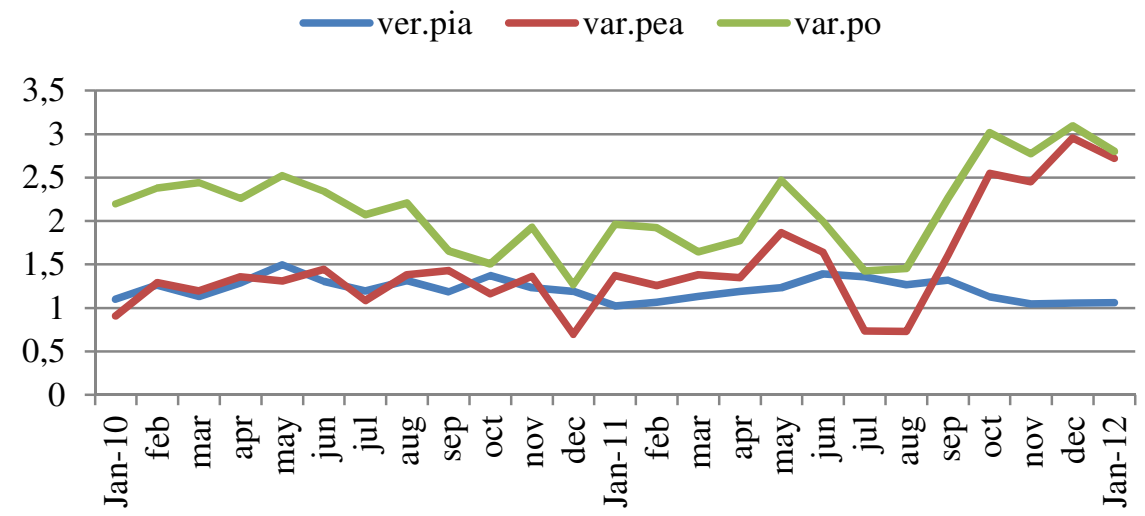

Fonte: IBGE (2013). Elaboração própria.

As demais evidências acerca dos indicadores de desemprego utilizados nessa pesquisa legitimam os argumentos da força causal do crescimento econômico sobre a formalização do emprego, como demonstram os resultados de redução do desemprego ilustrados nos Gráficos 4 e 5. O Gráfico 6 revela a evolução da taxa de desocupação, mostrando que a mesma se reduziu de forma mais lenta após 2010, o que deve estar associado, em grande medida, à desaceleração do crescimento do PIB nos anos 2011 e 2012. Mesmo assim, os dados mostram que houve redução da taxa de desocupação no Brasil ainda no ano de 2012.

\section{Gráfico 4}

Taxa de desocupação das regiões metropolitanas brasileiras investigadas pela PME para pessoas de 10 anos de idade ou mais na semana de referência nos anos de 2010, 2011 e 2012

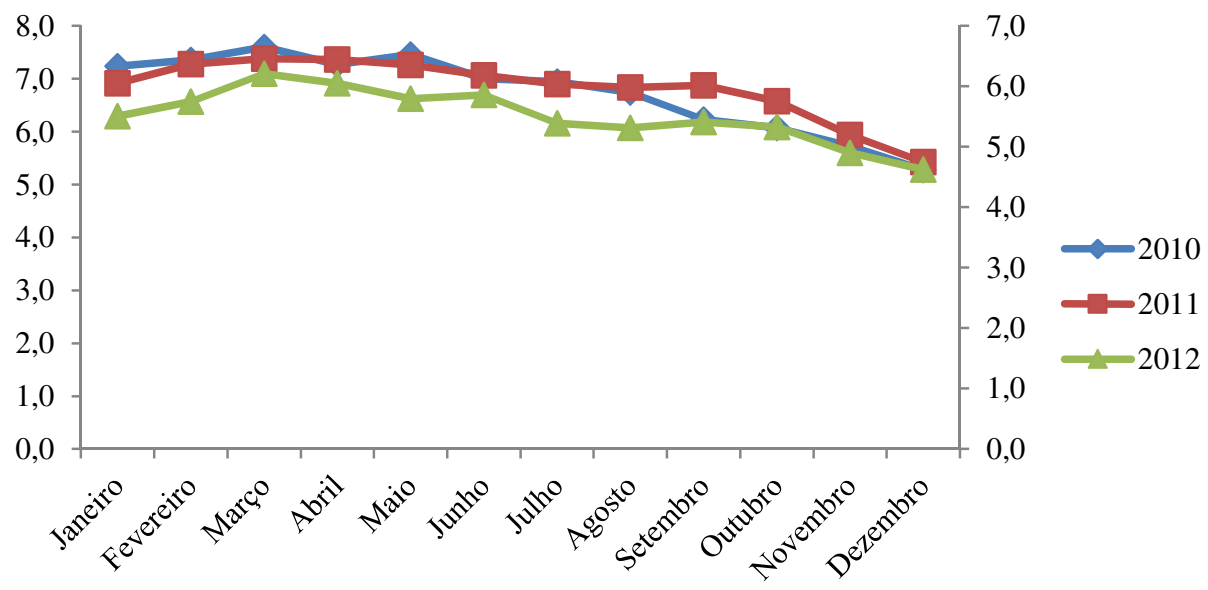

Fonte: IBGE (2013). Elaboração própria. 
Entretanto, tomando-se como base o que foi discutido na seção anterior, uma análise mais criteriosa do desemprego no país deveria levar em conta indicadores mais precisos do fenômeno do desemprego (não apenas o desemprego aberto).

O Gráfico 5 mostra que todos os tipos de desemprego medidos pelas PEDs vêm caindo ao longo do período considerado, mas também revela que ainda persistem significativas diferenças entre as taxas de desemprego aberta e total ${ }^{32}$. Em janeiro de 2009, por exemplo, quando o país ainda sentia fortemente os impactos da crise financeira internacional, a taxa de desemprego aberta era de $8,9 \%$, enquanto a total registrava 13,1\%. Em dezembro de 2010, passado os efeitos da crise, este diferencial entre as taxas havia se reduzido para 2,9 p.p. $(10,1 \%$ total contra $7,2 \%$ aberto), mas ainda assim era significativo, da mesma forma que ocorria ainda em dezembro de 2012 e janeiro de 2013.

\section{Gráfico 5}

Indicadores de desemprego a partir das taxas de desemprego oculto (pelo trabalho precário e pelo desalento), desemprego aberto e desemprego total, expressos em valores percentuais de janeiro de 2009 a janeiro de 2013

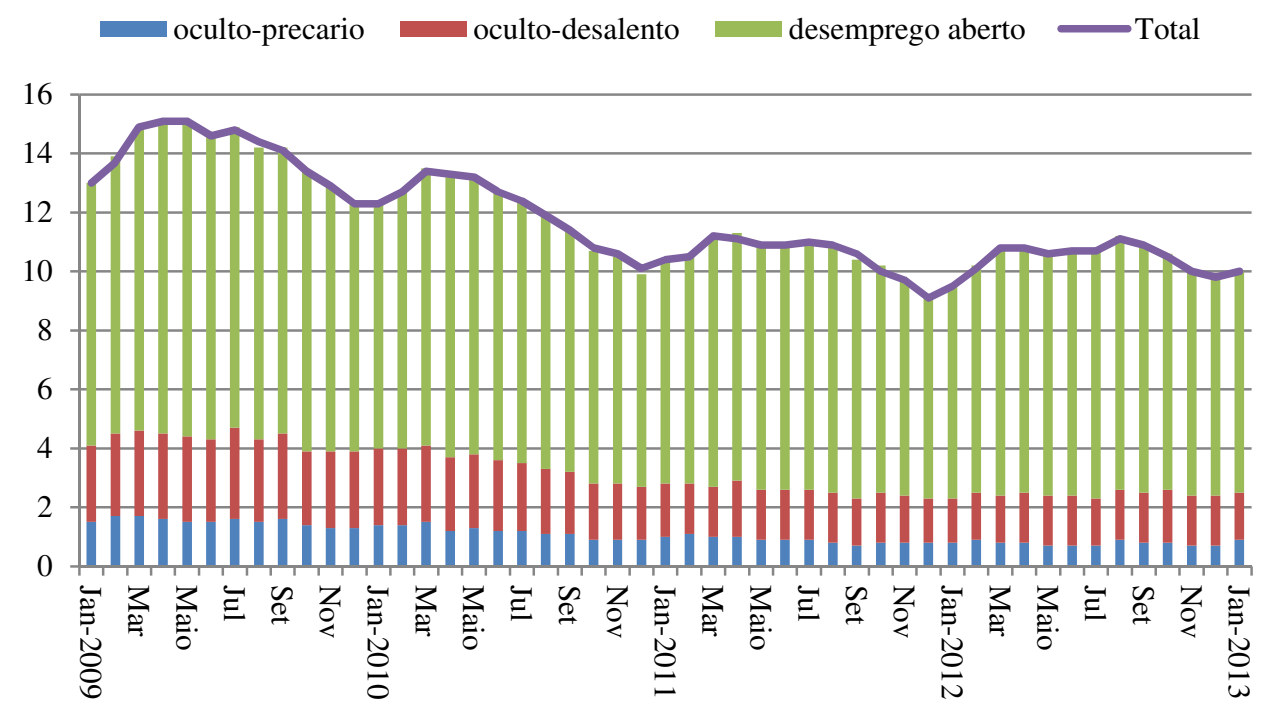

Fonte: Convênio Dieese-Seade; MTE/FAT e convênios regionais. Elaboração própria.

Esta queda no diferencial das taxas é resultante de um recuo tanto nos indicadores de desemprego oculto pelo trabalho precário quanto pelo desalento, mas o gráfico revela ainda a existência de parcela importante de subutilização da força de trabalho, segundo os critérios do Prealc.

(32) O Gráfico 5 informa os dados do conjunto das PEDs a cada mês, desde janeiro de 2009. 
Para finalizar esta subseção, seria interessante destacar um caso específico e bastante característico ${ }^{33}$ - do mercado de trabalho brasileiro: trata-se da ainda expressiva participação do emprego doméstico no conjunto da ocupação, embora declinante segundo indicam os dados da PME (Tabela 5) ou os dados da PNAD (ver Tabela 2$)^{34}$. Tal situação revela uma das modalidades existentes de subutilização ${ }^{35}$ de mão de obra no mercado de trabalho brasileiro em virtude da falta de oportunidades decorrentes dos condicionantes históricos do subdesenvolvimento brasileiro. O crescimento econômico do período considerado andou junto com a redução, demonstrada na Tabela 5 , da proporção de empregos domésticos no conjunto da ocupação. Devem ser feitas, porém, algumas ponderações. Em primeiro lugar, para o fato de que mesmo diante de um breve período (como o caso isolado do ano de 2009) de perda de dinamismo econômico, a parcela de emprego doméstico no conjunto do emprego já aponta para uma trajetória ascendente; além disso, os dados desta tabela não demonstram as elevadas desigualdades existentes para a participação deste indicador nos respectivos mercados de trabalho regionais. Por fim - mas também muito importante -, deve-se lembrar que esta forma de ocupação tem expressiva predominância feminina. Todos estes elementos são reveladores da heterogeneidade do mercado de trabalho brasileiro, que se manifesta de diversas formas, tornando pouco rigorosas certas afirmações generalizantes que defendiam a ideia de que o mercado de trabalho brasileiro estava em situação de pleno emprego ${ }^{36}$. A presença de contingente significativo de emprego doméstico, mesmo depois de um período de crescimento econômico relativamente longo (e com taxas de variação do PIB, em média, superiores às que vigoraram nos anos de 1980 e 1990), revela mais um fator que simboliza a persistência de um alto grau de subutilização de mão de obra na economia brasileira.

(33) Só para ilustrar uma comparação, o emprego doméstico, nos países europeus desenvolvidos ou mesmo nos EUA, representa menos do que $2 \%$ do total de ocupados dos respectivos mercados de trabalho nacionais.

(34) A tendência mostra-se inequivocamente declinante, mas uma observação mais atenta revela que, no ano de 2009, quando a economia sofreu uma brusca desaceleração, a participação do emprego doméstico no conjunto das ocupações voltou a subir (tanto pelos dados da PNAD quanto pelos dados da PME) - situação que revela mais um aspecto da precariedade do mercado de trabalho brasileiro.

(35) Ou de uso "inadequado", do ponto de vista tipicamente capitalista, conforme Souza (1980a).

(36) Sem contar ainda que não é adequado considerar o mercado de trabalho brasileiro como algo homogêneo, dadas as elevadas desigualdades setoriais, regionais e ocupacionais existentes no mesmo, conforme se pretende destacar neste estudo. 


\section{Tabela 5}

Participação relativa (em \%) do emprego doméstico no total da ocupação segundo a PME

\begin{tabular}{ll}
\hline dezembro de 2004 & 8,1 \\
dezembro de 2005 & 8,1 \\
dezembro de 2006 & 8,1 \\
dezembro de 2007 & 7,9 \\
dezembro de 2008 & 7,3 \\
dezembro de 2009 & 7,8 \\
dezembro de 2010 & 7,2 \\
dezembro de 2011 & 6,7 \\
dezembro de 2012 & 6,5 \\
\hline
\end{tabular}

Fonte: Pesquisa Mensal de Emprego (PME)/IBGE.

Elaboração própria.

\subsection{Evolução regional do emprego formal no Brasil}

A partir de uma análise dos dados do CAGED, é fácil constatar que o uso de uma taxa de desemprego nacional para avaliar uma situação de pleno emprego, mesmo que tal estatística de fato oficialmente existisse, representaria uma situaçãosíntese que seria, de fato, pouco rigorosa se esta condição de inserção no mercado de trabalho for avaliada de forma desagregada regionalmente. Isto ocorre porque o ritmo de crescimento do emprego na economia brasileira pode ser diferente dependendo de cada região do Brasil. De fato, tomando-se como base as estatísticas de emprego formal divulgadas pelo Ministério do Trabalho, nota-se que, ao longo do período em análise neste artigo, o ritmo de criação de postos de trabalho na economia brasileira diferiu bastante segundo as diferentes regiões brasileiras, conforme mostra o Gráfico 6.

\section{Gráfico 6}

Criação líquida de empregos formais por regiões brasileiras entre fevereiro de 2010 e fevereiro de 2013

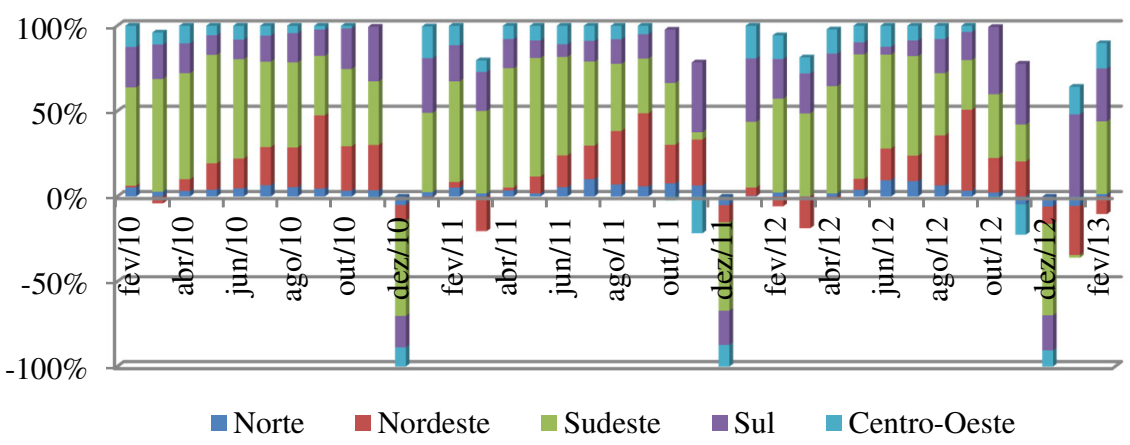

Fonte: Caged. Elaboração própria. 


\section{Conclusões}

A persistência, no mercado de trabalho brasileiro, em todas as suas diferentes regiões, de um elevado contingente de pessoas que ainda se inseriam de forma precária e informal no espaço ocupacional desautoriza, rigorosamente, a afirmação de que a economia brasileira tenha atingido o pleno emprego em algum momento no período analisado.

A informalidade, neste artigo, foi tratada como uma forma de manifestação de subutilização de mão de obra, segundo tradição inaugurada pelas pesquisas do PREALC, que serviram como base teórica para a avaliação da hipótese do pleno emprego na economia brasileira no período aqui estudado.

Um dos problemas que levam ao equívoco ou à falta de rigor na afirmação segundo a qual a economia brasileira atual estaria operando sob pleno emprego decorre do fato de que, invariavelmente, a taxa de desemprego usualmente utilizada na verdade representa uma taxa de desocupação, ou seja, uma taxa de desemprego aberto, aos moldes das taxas habitualmente captadas nos compêndios internacionais para descrever a situação de mercados de trabalho em países desenvolvidos.

No Brasil, tanto o IBGE quanto as PEDs metropolitanas calculam taxas de desemprego aberto, neste caso com metodologias e resultado semelhantes. Além de ser difícil e controverso estimar-se qual seria a taxa de desemprego referente à situação de pleno emprego (uma das formas de se "definir" a taxa de pleno emprego, segundo certa literatura tradicional sobre mercado de trabalho, seria por meio do consagrado acrônimo Nairu - em inglês, non-accelerating inflation rate of unemployment - para designar a taxa de desemprego abaixo da qual a economia passaria a operar com inflação cada vez maior, ou seja, a partir de quando estivesse em situação de pleno emprego), deve-se também ponderar que a opção por uma avaliação da dimensão do desemprego por meio da taxa de desemprego aberto acaba subestimando - conforme se procurou argumentar neste artigo - a parcela de trabalho na sociedade que ainda poderia ser mobilizada pela atividade produtiva e que se encontra, porém, disfarçada na forma da execução de diversas modalidades de subemprego, "bicos", jornadas de trabalho parciais contra a sua própria vontade e necessidade econômica, ou seja, uma parcela relevante do fator trabalho ainda está sendo subutilizada. Ademais, deve-se também destacar que ainda há um contingente não desprezível de pessoas registradas, pelos critérios da PME, na condição de inatividade, a qual, muitas vezes, representa uma situação apenas temporária da situação do trabalhador e que pode se alterar a qualquer momento, dependendo do estágio em que se encontra o ciclo econômico, da composição familiar da renda e de outros diversos fatores.

O debate sobre pleno emprego foi estimulado, nos anos recentes, pelo fato de diversos indicadores revelarem melhoria no mercado de trabalho brasileiro no 
período tratado neste artigo, como a redução da taxa de desemprego para os patamares mais baixos das séries históricas disponíveis, em um contexto também de progressivo processo de ampliação da formalização do emprego em todas as regiões do país.

Para que estes resultados tivessem se concretizado, foi muito importante que a economia brasileira tenha adentrado uma trajetória de crescimento que, embora ainda estivesse abaixo da exibida por países de grau de desenvolvimento econômico semelhante ao do Brasil, posicionou-se acima da média da economia brasileira das duas últimas décadas do século XX.

Este artigo defende a ideia de que, em um mercado de trabalho com as características do mercado de trabalho brasileiro, a metodologia mais adequada para avaliar o fenômeno do desemprego é a desenvolvida pela Fundação SEADE/DIEESE, que deu origem à Pesquisa de Emprego e Desemprego (PED) da Região Metropolitana de São Paulo e, depois, às respectivas PEDs de outras Regiões Metropolitanas. Esta é a principal razão pela qual este estudo defende a ideia de serem inadequadas ou imprecisas as afirmações segundo as quais a economia brasileira teria atingido, em 2012, o pleno emprego (embora não se deva destacar a possibilidade de que, em setores específicos, possa ter havido de fato falta de mão de obra para algumas funções).

O exercício econométrico que foi feito também tem papel importante a desempenhar nessa discussão. O exercício apresentado procura relacionar a evolução da taxa de crescimento do PIB com a ocupação, tomando os dados das Pesquisas Mensais de Emprego (PME), realizadas pelo IBGE, e dados mensais de PIB do IPEA.

Os resultados encontrados pelo exercício econométrico revelaram ter ocorrido uma relação significativa do crescimento do PIB sobre a ocupação brasileira, como demonstra a interpretação keynesiana apoiada no Princípio da Demanda Efetiva, segundo o qual o nível de emprego é determinado pelas decisões de gastos tomadas pelos agentes econômicos, conforme se depreende da leitura da Teoria Geral. Em outras palavras, o emprego seria determinado, a rigor, fora do âmbito estrito do mercado de trabalho.

A contribuição teórica consolidada na Teoria Geral, porém, não se mostra suficiente para discutir as peculiaridades de um mercado de trabalho como o brasileiro, conforme se procurou argumentar neste artigo. A existência de uma elevada informalidade (sem contar outras formas de manifestação de subutilização de mão de obra, como o emprego doméstico - mesmo que dentro da lei ${ }^{37}$ ) exige uma

(37) Ou seja, com contrato de trabalho definido por registro em carteira, o que, a rigor, simboliza a formalização das relações de trabalho no Brasil. 
formulação teórica específica para sua compreensão. Esta formulação teórica vem da tradição dos estudos do Prealc, que nortearam a interpretação sobre a hipótese do pleno emprego considerada neste artigo.

A interpretação do Prealc acerca das relações entre os setores formal e informal de mercados de trabalho de países subdesenvolvidos advoga que é o setor capitalista (formal) que delimita o espaço econômico do setor informal (a dimensão ocupacional do mesmo, por outro lado, dependerá de diversos outros fatores, entre os quais se destacam fatores demográficos, aspectos institucionais do funcionamento da atividade econômica e também da regulação do mercado de trabalho, etc.). Esta formulação teórica permite compreender a complexidade dos movimentos do fator trabalho em uma ampla gama de formas de inserção no mercado de trabalho, o que exige uma maneira mais rigorosa de se medir a dimensão do desemprego, que não deve ser avaliado simplesmente pela sua dimensão de desemprego aberto.

A persistência ainda de não desprezível contingente de subutilização da mão de obra (resumidos em informalidade e em emprego doméstico), mesmo depois de um período de crescimento econômico, manifesta uma das diversas formas de fragilidade do mercado de trabalho brasileiro. Mesmo a possibilidade de que uma parcela desse segmento informal do mercado de trabalho esteja nesta situação por escolha própria (situação admitida por diferentes linhas teóricas que se debruçaram sobre esta importante questão) não invalida a possibilidade de que parcela relevante dos trabalhadores do setor informal esteja nesta situação por causa de falta de oportunidades no setor formal. Sendo assim, podemos afirmar que a leitura também de autores de diferentes posições ideológicas em relação aos que foram tomados como referência teórica para a análise dos dados da economia brasileira recente permite sustentar a ideia de que a ocupação no setor informal representa subutilização de mão de obra no mercado de trabalho brasileiro. E, portanto, a persistência de uma parcela ainda significativa da mão de obra atuando no setor informal do mercado de trabalho brasileiro respalda a afirmação de que a economia brasileira não atingiu o estágio de pleno emprego no período analisado.

\section{Bibliografia}

BALL, L. e MANKIW, N.G. The NAIRU in Theory and Practice. Journal of Economic Perspectives, v. 16, n. 4, p. 115-136, 2002.

BALTAR, P. E. A. O mercado de trabalho no Brasil dos anos 90. Tese (LivreDocência)-Instituto de Economia, Universidade Estadual de Campinas, Campinas, 2003.

. Formação, estruturação e crise do mercado de trabalho no Brasil. In.

DEDECCA, C. S.; PRONI, M W. Políticas públicas e trabalho. Campinas: Unicamp/IE, Brasília: MTE, 2006, p. 9-28. 
BARBOSA, A. de F. De "setor" para "economia informal": aventuras e desventuras de um conceito. São Paulo: USP, 2009. Mimeografado.

BARBOSA de OLIVEIRA, C. A. Formação do mercado de trabalho no Brasil. In: OLIVEIRA, M. A. Economia \& Trabalho. Campinas: Unicamp. Instituto de Economia, 1988.

BARROS, R. P.; MELLO, R.; PERO, V. Informal labor contracts: a solution or a problem? Ipea, 1993. (Texto para Discussão, n. 291).

; SEDLACEK, G. L.; VARANDAS, S. Segmentação e mobilidade no mercado de trabalho: a carteira de trabalho em São Paulo. Pesquisa e Planejamento Econômico, v. 20, n. 3, p. 87-103, 1990.

BASTOS, C. P.; BRITTO, G. Introdução. In: AGARWALA, A. N.; SINGH, S. P. (Org.). A economia do subdesenvolvimento. 2. ed. rev. Rio de Janeiro: Ed. Contraponto: Centro Internacional Celso Furtado, 2010.

BELLUZZO, L. G. M. Ensaios sobre o capitalismo no século XX. São Paulo: Ed. Unesp; Campinas (SP): Ed. Unicamp, Instituto de Economia, 2004.

. O fim da moral vitoriana. In:

. Ensaios sobre o capitalismo no

século XX. São Paulo: Ed. Unesp; Campinas (SP): Ed. Unicamp, Instituto de Economia, 2004.

BEVERIDGE, W. Full employment in a free society. New York: W.W. Norton \& Company, Inc., 1945.

BREGGER, J. E.; HAUGEN, S. E. BLS introduces new range of alternative unemployment measures. Monthly Labour Review, Oct. 1995.

CACCIAMALI, M. C. Um estudo sobre o setor informal urbano e formas de participação na produção. Tese (Doutoramento)-FEA, USP, 1982.

. Setor informal urbano e formas de participação na produção. São Paulo:

Ed. IPE, 1983. (Série Ensaios Econômicos, n. 26).

CARDOSO DE MELlO, J. M. O capitalismo tardio. São Paulo: Ed. Brasiliense, 1982.

CARLIN, W.; SOSKICE, D. Macroeconomics and the wage bargain. Ed. Oxford University Press, 1990.

CARNEIRO, F. G.; HENLEY, A. Modelling formal vs. informal employment and earnings: microeconomic evidence for Brazil. IN: ENCONTRO NACIONAL DE ECONOMIA, Anpec, 2001. Anais...

DEDECCA, C. S. O desemprego na Pesquisa de Emprego e Desemprego. São Paulo em Perspectiva, v. 20, n. 4, p. 46-57. out./dez. 1996.

DEDECCA, C. S.; FERREIRA, S. P. Transição demográfica e crescimento da população economicamente ativa. São Paulo em Perspectiva, v. 3, n. 3, p. 79-83, jul./set. 1989. 
FUNDAÇÃO SEADE. Principais conceitos: o que é a Pesquisa de Emprego e Desemprego. 1998. Acesso: http://www.seade.gov.br/produtos/ped/pedmv98/ conceito.html.

GUIMARÃES, N. A. Novas formas, novas medidas?: desemprego, trajetórias ocupacionais e experiências na produção de informações. São Paulo em Perspectiva, São Paulo, Fundação Seade, v. 20, n. 4, p. 103-126, out./dez. 2006.

GUJARATI, D. N.; PORTER, D. C. Econometria básica. 5. ed. Porto Alegre: Makron Books, 2011.

HOBSBAWM, E. Era dos extremos. São Paulo: Companhia das Letras, 1995.

INSTITUTO BRASILEIRO DE GEOGRAFIA E ESTATÍSTICA (IBGE). Pesquisa Mensal de Emprego. Série relatórios Metodológicos. 2. ed. v. 23. Rio de Janeiro, 2007. em: 1 abr. 2013.

Pesquisa Mensal de Emprego. Disponível em www.ibge.gov.br. Acesso

INSTITUTO DE PESQUISA ECONÔMICA APLICADA (IPEA). Dados macroeconômicos. Disponível em: www.ipeadata.org. Acesso em: 01 abr. 2013.

Considerações sobre o pleno emprego no Brasil. Brasília (DF), fev. 2012. (Comunicados do Ipea, n. 135). Disponível em: http://www.ipea.gov.br/portal limages/stories/PDFs/comunicado/120216_comunicadoipea135.pdf

KEYNES, J. M. A teoria geral do emprego, do juro e da moeda (Os economistas). São Paulo: Nova Cultural, 1988 [1936].

KREIN, J. D.; PRONI, M. W. Economia informal: aspectos conceituais e teóricos. Série Trabalho Decente no Brasil. Escritório da OIT no Brasil, 2010. (Documento de Trabalho, 4).

MACEDO e SILVA, A. C. Macroeconomia sem equilíbrio. Petrópolis (RJ): Vozes; Campinas (SP): Fecamp, 1999.

MALONEY, W. F. Does informality imply segmentation in urban labor markets? Evidence from sectoral transitions in Mexico. World Bank Economic Review, v. 13, n. 2, p. 275-302, 1999.

MINISTÉRIO DO TRABALHO E EMPREGO. Impactos nos resultados com a inclusão da Região Metropolitana de Fortaleza. (Nota técnica, n. 1). Disponível em: http://portal.mte.gov.br/data/files/FF8080812B8D19D2012BA5E107371493/PED nt_01.pdf.

MINISTÉRIO DO TRABALHO E EMPREGO. CAGED e PED: diferenças metodológicas e possibilidades de comparação. Disponível em: http://www.mte.gov.br/empregador/caged/baseestatistica/conteudo/5268.asp.

MONTAGNER, P.; BRANDÃO, S. M. C. Desemprego: novos aspectos de um velho problema. São Paulo em Perspectiva, v. 10, n. 1, p. 36-45, abr./jun. 1996. 
OIT (1972). Employment, income and equality: a strategy for increasing productive employment in Kenia. Genebra: OIT, 1972.

PINTO, A. Heterogeneidade estrutural e modelo de desenvolvimento crescente. In: SERRA, J. (Coord). América Latina: ensaios de interpretação econômica. 2. ed. Rio de Janeiro: Paz e Terra, 1979.

SOARES, F.V. Do informal Workers Queue for Formal Jobs in Brazil? Ipea, 2004. (Texto para Discussão, n. 1021).

SORRENTINO, C. International comparisons of unemployment indicators. Monthly Labour Review, Mar. 1993.

Review, Aug. 1995.

International unemployment indicators, 1983-93. Monthly Labour

SOUZA, P. R. A determinação dos salários e do emprego nas economias atrasadas. Tese (Doutoramento)-Unicamp, 1980a.

Emprego, salários e pobreza. São Paulo: Ed. Hucitec/Funcamp: 1980 b.

STIRATI, A. Inflation, unemployment and hysteresis: an alternative view. Review of Political Economy, 2001.

TANNURI-PIANTO, M. E.; PIANTO, D. Informal employment in Brazil - A choice at the top and segmentation at the bottom: a quantile regression approach. In: ENCONTRO BRASILEIRO DE ECONOMETRIA, 24, 2002. Anais... v. 2.

TOKMAN, V. E. La dinâmica del mercado de trabajo urbano: el sector informal urbano em América Latina. Santiago: Prealc, 1977.

. An exploration into the nature of Formal-Informal sector relationship. World Development, v. 6, n. 9/10, Oct. 1978. jul./sept. 1987.

. Sector informal: 15 años después. El Trimestre Económico, v. XV, n. 15,

TROYANO, A. A. Flexibilidade do emprego assalariado. São Paulo em Perspectiva, v. 5, n. 2, p. 84-95, abr./jun. 1991.

Como medir o desemprego numa economia subdesenvolvida. São Paulo em Perspectiva, v. 2, n. 3, p. 13-15, jul./set. 1988.

TOKMAN, V. E. A trajetória de uma pesquisa: avanços e obstáculos. São Paulo em Perspectiva, v. 4, n. 3/4, p. 69-74. jul./dez. 1990.

. Pesquisa de emprego e desemprego: metodologia, conceitos e aferições dos resultados. São Paulo em Perspectiva, v. 6, n. 4, p. 124-134. out./dez. 1992.

ULYSSEA, G. Informalidade no mercado de trabalho brasileiro: uma resenha da literatura. Revista de Economia Política, v. 26; n. 4 (104), out./dez. 2006. 